\title{
Offshore Transport of Shelf Water by Deep-Ocean Eddies ${ }^{\mathscr{O}}$
}

\author{
DEEPAK A. CHERIAN \\ Physical Oceanography, Massachusetts Institute of Technology/Woods Hole Oceanographic Institution \\ Joint Program in Oceanography, Cambridge/Woods Hole, Massachusetts \\ K. H. BRINK \\ Woods Hole Oceanographic Institution, Woods Hole, Massachusetts
}

(Manuscript received 5 April 2016, in final form 17 October 2016)

\begin{abstract}
At continental margins, energetic deep-ocean eddies can transport shelf water offshore in filaments that wrap around the eddy. One example is that of Gulf Stream warm-core rings interacting with the Mid-Atlantic Bight shelf. The rate at which shelf water is exported in these filaments is a major unknown in regional budgets of volume, heat, and salt. This unknown transport is constrained using a series of idealized primitive equation numerical experiments wherein a surface-intensified anticyclonic eddy interacts with idealized shelf-slope topography. There is no shelfbreak front in these experiments, and shelf water is tracked using a passive tracer. When anticyclones interact with shelf-slope topography, they suffer apparent intrusions of shelf-slope water, resulting in a subsurface maximum in offshore transport. The simulations help construct an approximate model for the filament of exported water that originates inshore of any given isobath. This model is then used to derive an expression for the total volume of shelf-slope water transported by the eddy across that isobath. The transport scales with water depth, radius, and azimuthal velocity scale of the eddy. The resulting expression can be used with satellite-derived eddy properties to estimate approximate real-world transports ignoring the presence of a shelfbreak front. The expression assumes that the eddy's edge is at the shelf break, a condition not always satisfied by real eddies.
\end{abstract}

\section{Introduction}

The coastal ocean is salty, much more so than an estuary. Since river inputs are fresh and surface fluxes [i.e., evaporation minus precipitation $(E-P)]$ can be unimportant (Lentz 2010), there must exist an onshore salt flux across the shelf break, the importance of which to shelf budgets around the world is variable (Brink 1998). Mesoscale deep-ocean eddies at the shelf break contribute to this flux by transporting fresh shelf water offshore and moving salty slope water onshore. Offshore fluxes are regularly observed in the Mid-Atlantic Bight off the northeastern United States [e.g., Joyce et al. (1992) and SST imagery] and in the Gulf of Mexico

Supplemental information related to this paper is available at the Journals Online website: http://dx.doi.org/10.1175/JPO-D-16-0085.s1.

Corresponding author e-mail: Deepak A. Cherian, dcherian@ whoi.edu
(Vukovich and Waddell 1991; Frolov et al. 2004). These are only two locations of many-along the East Australian shelf (Olson 1991), the Gulf of Alaska (Okkonen et al. 2003), the Antarctic shelf (Stewart and Thompson 2015), and so on - where the process might be important.

For example, the Gulf Stream is unstable and frequently its meanders pinch off as large eddies, or rings, that are approximately $1000 \mathrm{~m}$ deep and $60-90 \mathrm{~km}$ in radius (Fig. 1). Those that are not quickly reabsorbed by the Gulf Stream or its meanders move westward toward the shelf break off the northeastern United States. Upon encountering the shelf break, they move southwestward parallel to the shelf break until the Gulf Stream reabsorbs them at approximately $37^{\circ} \mathrm{N}$. During their southwestward transit, the rings transport cold shelf water offshore in filaments, termed streamers (Joyce 1984). In some cases (Fig. 1), the filaments roll up into secondary cyclonic vortices (Evans et al. 1985; Garfield and Evans 1987; Kennelly et al. 1985). Rings also transport warm, salty slope and eddy water onto the 

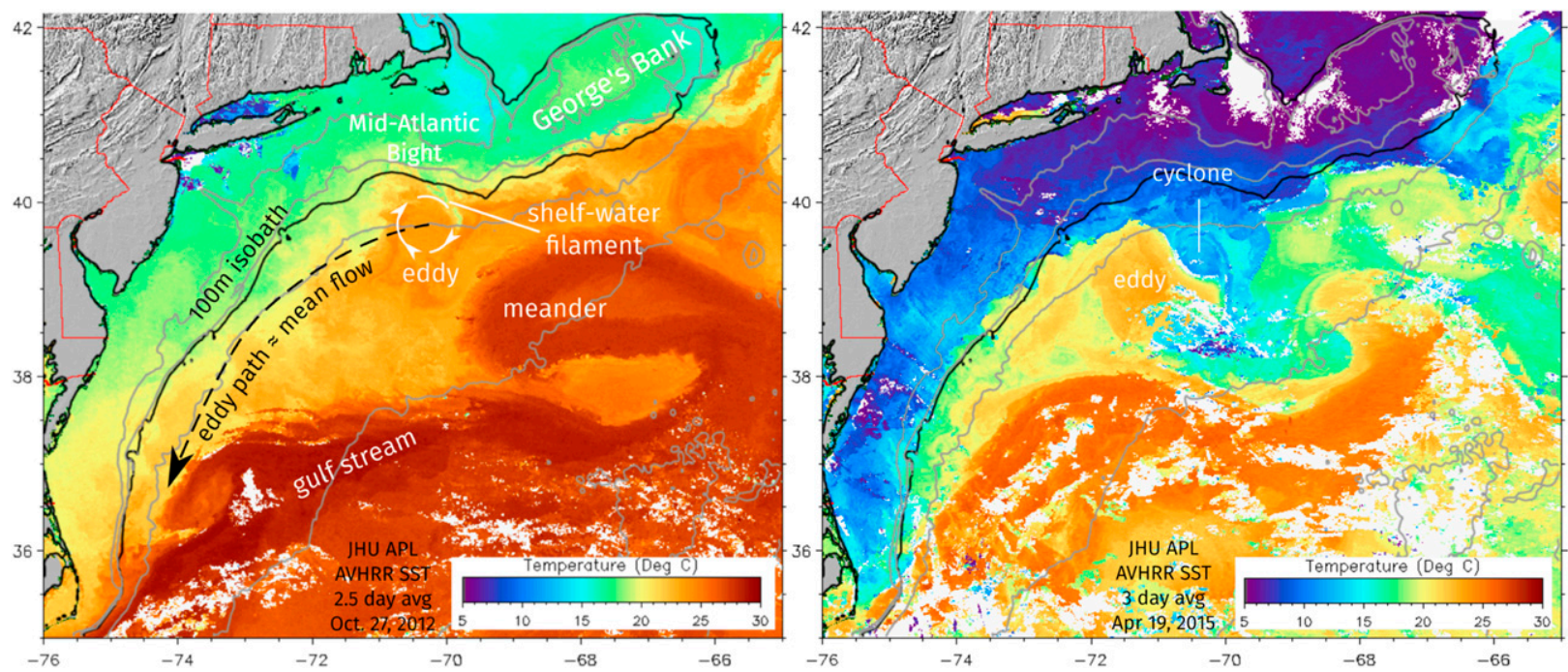

FIG. 1. Two SST images illustrating cross-shelfbreak transport of cold shelf water by a Gulf Stream warm-core ring (eddy). The images have been modified from those created by the Johns Hopkins University Applied Physics Laboratory. The thick black solid contour is the 100-m isobath. The gray contours are the 50-, 80-, 2000-, 4000-, and 5000-m isobaths. (left) The offshore flow occurs in a filament termed streamer. (right) The filament has wrapped up into a cyclone.

shelf to the southwest of the eddy center (Oey and Zhang 2004; Zhang and Gawarkiewicz 2015).

How important are such transports to shelf budgets of volume, heat, and salt? For the Mid-Atlantic Bight, Lentz (2010) found that an onshore salt flux of $0.7 \times$ $10^{-2} \mathrm{~kg} \mathrm{~m}^{-2} \mathrm{~s}^{-2}$ at the $100-\mathrm{m}$ isobath (approximately the shelf break) - driven by time-dependent flows-is required to close the salt balance along the 50- and $70-\mathrm{m}$ isobaths. The volume budget of Brink (1998) requires the offshore flux of shelf water to be 0.04$0.11 \mathrm{~Sv}\left(1 \mathrm{~Sv}=10^{6} \mathrm{~m}^{3} \mathrm{~s}^{-1}\right)$. Various cross-frontal exchange processes are evidently responsible for these fluxes. Mesoscale eddy-driven exchange could account for some of the unexplained salt flux in Lentz (2010) since, on average, seven rings interact with the MidAtlantic Bight shelf south of George's Bank (Fig. 1) in a year (Garfield and Evans 1987). Its episodic nature makes field observations of such exchange difficult, and the in situ observational record is sparse. Only two estimates, namely, those of Joyce et al. (1992) and Lee and Brink (2010), use ADCPs to obtain direct velocity measurements. For the same salinity threshold, $S<33$, both estimates are of similar magnitude: 0.03 and $0.07 \mathrm{~Sv}$. Since satellite observations are currently the best record of these exchanges, it is of interest to use them to obtain estimates of cross-isobath fluxes, weather permitting.

We use idealized numerical simulations of a single eddy to examine the structure of the streamer transporting shelf-slope water offshore. This is a more indepth parameter space exploration when compared to
Wei and Wang (2009) and a primitive equation extension of the barotropic simulations of Wang (1992). Unlike Zhang et al. (2011), the coastline here is straight. On occasion, multiple eddies interact with the shelf break off the Mid-Atlantic Bight. Here, the presence of multiple eddies and mean flows is ignored for simplicity. We show that in every simulation the streamer appears to intrude into the eddy. The intrusion results in a subsurface maximum in offshore transport. We present a parameterization that, with some assumptions about the eddy's vertical structure, enables the use of available satellite-derived eddy properties (radius and azimuthal velocity) to estimate the amount of water crossing isobaths. For simplicity, there is no shelfbreak front in our simulations.

\section{Experiment design}

We use an idealized configuration of the hydrostatic, primitive equation Regional Ocean Modeling System (ROMS; Shchepetkin and McWilliams 2005). It solves the equations [subscripts represent differentiation: $\rho=\rho_{0}+\rho(x, y, z, t)$ and $\left.\nabla=\partial_{x} \hat{i}+\partial_{y} \hat{j}\right]$

$$
\begin{aligned}
u_{t}+ & u u_{x}+v u_{y}+w u_{z}-f v \\
= & -\frac{1}{\rho_{0}} p_{x}+\left(A_{v} u_{z}\right)_{z}+\nabla \cdot\left(A_{H} \nabla u\right) \\
& +\underbrace{\nabla \cdot \sqrt{A_{B}} \nabla\left(\nabla \cdot \sqrt{A_{B}} \nabla u\right)}_{\text {biharmonic viscosity }},
\end{aligned}
$$



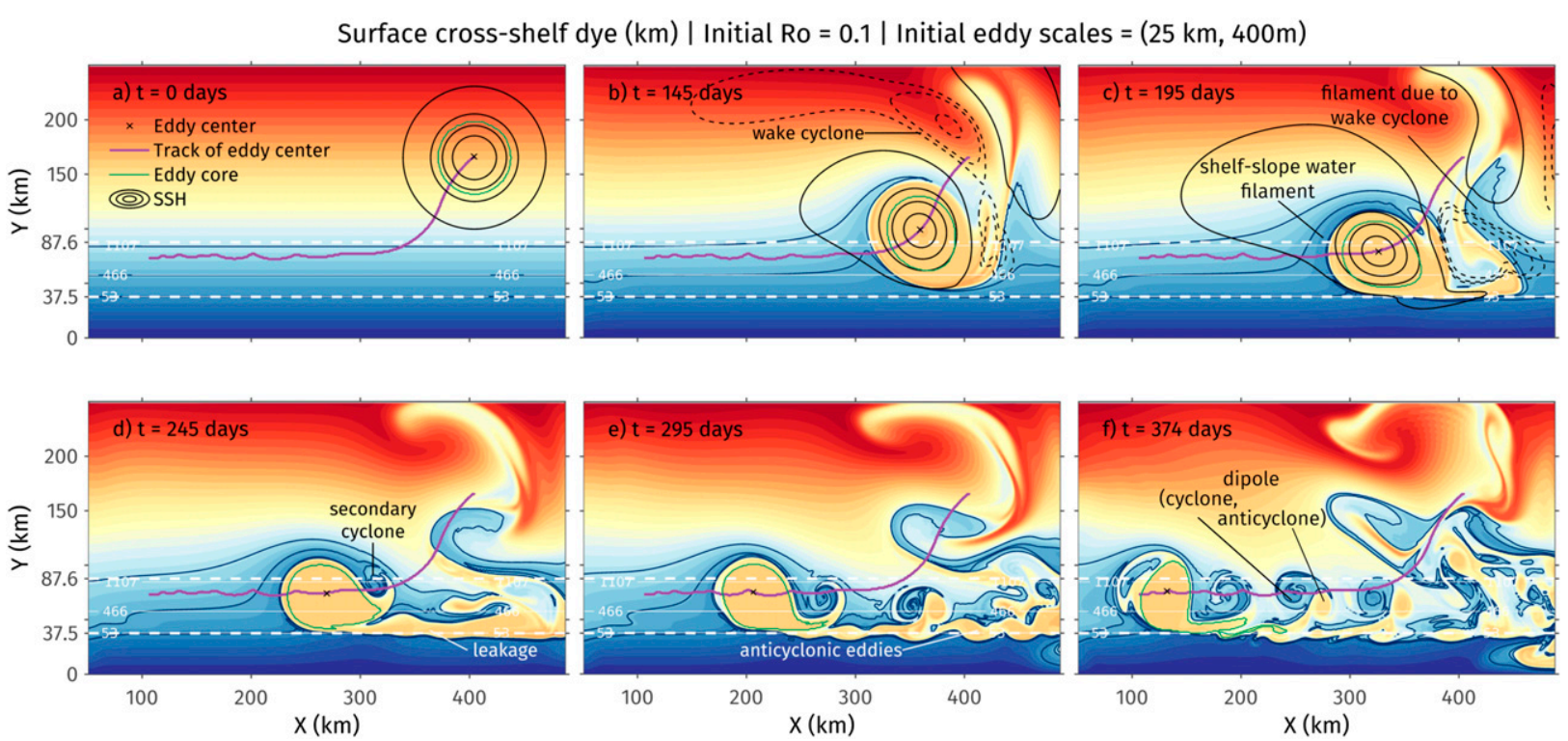

FIG. 2. Snapshots of surface cross-shelf dye field for ew-34. Bathymetric contours are in gray; dashed lines mark the shelf and slope break. The green contour identifies the core of the eddy (section 4a). Blue contours identify shelf-slope water parcels that started out at the marked isobaths. SSH is contoured in black; negative values are dashed. (a) Initially, each water parcel is tagged with its latitude. (b),(c) As the eddy moves southwestward, it homogenizes the dye within itself. The eddy advects shelf-slope water across isobaths and sheds eddy water along-shelf. (c),(d) The eddy sheds fluid forming a warm along-shelf current. The advected shelf-slope water forms a filament (blue contours). (d),(e) Cyclonic vortices containing shelf-slope water combine with anticyclonic fluid from the core of the eddy to form dipoles (section 5b). The process repeats, creating many dipoles that propagate away from the eddy. (f) The eddy water on the shelf at $x \approx 430 \mathrm{~km}$ is an artifact caused by imperfect open boundary conditions.

$$
\begin{gathered}
v_{t}+u v_{x}+v v_{y}+w v_{z}+f u \\
=-\frac{1}{\rho_{0}} p_{y}+\left(A_{\nu} v_{z}\right)_{z}+\nabla \cdot\left(A_{H} \nabla v\right) \\
+\nabla \cdot \sqrt{A_{B}} \nabla\left(\nabla \cdot \sqrt{A_{B}} \nabla v\right) \\
0=-p_{z}-\rho g \\
u_{x}+v_{y}+w_{z}=0, \quad \text { and } \\
\rho_{t}+u \rho_{x}+v \rho_{y}+w \rho_{z}=\left(\kappa_{\nu} \rho_{z}\right)_{z}+\nabla \cdot\left(\kappa_{H} \nabla \rho\right) \\
+\underbrace{\nabla \cdot \sqrt{\kappa_{B}} \nabla\left(\nabla \cdot \sqrt{\kappa_{B}} \nabla \rho\right)}_{\text {biharmonic diffusivity }} .
\end{gathered}
$$

The terms $(x, y, z)$ define a right-handed Cartesian coordinate system with $z$ being depth, $x$ is generally along isobath, and $y$ is cross isobath. The model domain is a $\beta$ plane with Coriolis frequency $f=f_{0}+\beta y ;(u, v, w)$ are velocities in $x, y$, and $z$, respectively; $p$ is pressure and $\rho$ is density. Here $A_{H}$ and $A_{B}$ are harmonic and biharmonic horizontal viscosity coefficients. Similarly, $\kappa_{H}$ and $\kappa_{B}$ are harmonic and biharmonic horizontal diffusivity coefficients. The variables $A_{\nu}$ and $\kappa_{\nu}$ are harmonic vertical viscosity and diffusivity coefficients. The main elements of the problem, namely, shelf-slope topography, anticyclonic eddy, and ambient stratification, are all reduced to the simplest possible form.

The topography is constructed using three straight lines to bound the shelf, the continental slope, and the deep ocean. The deep-ocean bottom is always flat. A four-point running mean applied six times smooths the intersections at the shelf break and slope break. The term shelf break refers to the intersection of the shelf and continental slope, while slope break refers to the intersection of the continental slope and the flat-bottomed deep ocean.

The eddy is a radially symmetric, surface-intensified, Gaussian temperature anomaly superimposed on background stratification $[\bar{\rho}(z)]$, as

$$
T_{\text {edd }}=T_{\text {amp }} \exp \left[-(r / L)^{2}-\left(z / L^{z}\right)^{2}\right]
$$

The horizontal length scale $L$ is specified, and the vertical scale is $L^{z}=\left(f_{0} L\right) /(N \sqrt{2})$, where $L / \sqrt{2}$ is the radius to maximum azimuthal velocity of the eddy. The density anomaly is balanced by a cyclogeostrophic velocity field determined after prescribing zero velocity at the bottom. The ambient buoyancy frequency $N^{2}$ is always constant. The eddy always starts in deep water, far from the topography, approximately one deformation radius away from the slope break (Fig. 2), so that its initial evolution is as over a flat-bottomed ocean (verified 
using a flat-bottom simulation). We let the eddy adjust to the $\beta$ plane in deep water before it impacts the slope, unlike previous $f$-plane studies (e.g., Oey and Zhang 2004) where the eddy starts on the slope.

Isolated anticyclonic eddies move southwestward on a $\beta$ plane (McWilliams and Flierl 1979; Nof 1983; Early et al. 2011), making the eddy translate across isobaths without a cross-isobath background flow. The southwestward motion renders two coastal locations moot: for a coast at the north or east, the eddy will move away from the shelf break. The topography must be placed at either the western or southern boundary of the domain for the eddy to encounter it. Most experiments described here use topography with a southern coast. With open eastern and western boundaries, this configuration allows Rossby waves radiated by the eddy (Flierl et al. 1983) to exit the domain, allowing the eddy to interact with undisturbed shelf-slope waters. The latter is not true for a western coast because it traps Rossby wave momentum that spins up flow features over the slope (section 9a; Cherian 2016). Qualitatively, our results hold for both orientations because the secondary flow features that develop once the eddy reaches the shelf break are too small to be influenced by $\beta$. Coastal orientation then ceases to matter.

The coastal boundary is a free-slip wall. The other three boundaries are open. Boundary conditions used at these open boundaries are an explicit Chapman condition for the free surface, a modified Flather condition for 2D momentum (Mason et al. 2010), and a combined radiation-nudging condition for tracers and 3D momentum (Marchesiello et al. 2001). To prevent noise at the open boundary from contaminating the solution, we use sponge layers as damping: 50-km-wide (40 points) regions with lateral Laplacian viscosity $A_{H}$ linearly increasing from 0 to $50 \mathrm{~m}^{2} \mathrm{~s}^{-1}$ and lateral Laplacian diffusivity $\kappa_{H}=0-5 \mathrm{~m}^{2} \mathrm{~s}^{-1}$.

For computational efficiency, a hyperbolic tangent function is used to stretch the horizontal grid spacing near the sponge layers at the open boundaries. Horizontal spacing is always at least $1 \mathrm{~km}$ and less than $2.5 \mathrm{~km}$. Our diagnostics are not very sensitive to changes in grid spacing (section $4 \mathrm{c}$ ). In the vertical, we distribute 72 grid points such that vertical grid spacing is smallest near the surface and largest near the bottom $(0.6-25 \mathrm{~m})$. A density Jacobian-based algorithm (Shchepetkin and McWilliams 2003) reduces the pressure gradient error. ${ }^{1}$ We use biharmonic lateral viscosity $\left(A_{B}=\right.$ $\left.4.4 \times 10^{6}-3 \times 10^{8} \mathrm{~m}^{4} \mathrm{~s}^{-1}\right)$ and diffusivity $\left(\kappa_{B}=1.2 \times 10^{3}-\right.$ $8 \times 10^{4} \mathrm{~m}^{4} \mathrm{~s}^{-1}$ ) along sloping vertical coordinate surfaces $^{2}$ to control noise outside the sponge layers. The values scale with grid cell size. The Laplacian

\footnotetext{
${ }^{1}$ ROMS option DJ_GRADPS.

${ }^{2}$ The s surfaces in ROMS terminology.
}

coefficients $A_{H}$ and $\kappa_{H}$ are 0 outside the sponge layers. When used, the bottom friction term is linear:

$$
\tau_{\text {bot }}=\rho_{0}\left(-r_{f} u,-r_{f} v\right) .
$$

There is no shelfbreak front, so shelf and slope waters are indistinguishable in density. Instead, each water parcel is tagged with its initial latitude using a passive tracer termed the cross-shelf dye. This dye traces shelf water, water parcels that initially start south of the shelf break, and slope water, parcels that are initially between the shelf and slope break.

We use a second passive tracer to track eddy water. This passive tracer is initialized with value 1 , where the temperature anomaly [(6)] is greater than some small value. In practice, not all of the dye with value 1 is carried with the eddy, but this conservative initial distribution lets us identify an eddy core that transports mass over long spatial and time scales. The eddy also homogenizes the cross-shelf dye within it, letting us distinguish it from the surrounding water.

\section{A typical simulation}

We conducted a series of simulations varying parameters such as velocity and length scales of the eddy, width, and topographic slopes of the shelf and continental slope; shelfbreak depth $H_{\mathrm{sb}}, \beta$, and bottom friction coefficient $r$; polarity of the eddy; geographic location of the coast; and background stratification (Table 1). The evolution of a deformation-scale eddy (initially 40-km radius and 340-m depth) in a simulation with no bottom friction and a southern coast is shown in Fig. 2 (ew-34 in Table 1, see the video in the supplemental information). The eddy's initial Rossby number is 0.1 (Table 2). The $40-\mathrm{km}$-wide shelf is flat. The water depth increases from $50 \mathrm{~m}$ at the shelf break to $1200 \mathrm{~m}$ in the deep-water region. The slope is $50 \mathrm{~km}$ wide and has a slope Burger number of 1.5 (Table 2).

Initially, the anticyclonic eddy moves southwestward on the $\beta$ plane. While doing so, it radiates Rossby waves westward, evident in the westward spreading of SSH contours (Fig. 2b). A wake cyclone is spun up to the eddy's eastern side by the advection of water parcels across the planetary PV gradient. The cyclone transports some slope water offshore in a filament visible at $x \sim 420 \mathrm{~km}$ in Fig. 2b. The eddy's southward motion stops when it reaches the shelf break, and after which it translates westward along the shelf break, presumably due to the image effect. The evolution of the eddy strongly resembles the contour dynamics simulations of Shi and Nof (1993, their Figs. 3 and 5), wherein a vertical wall abruptly cuts off the circulation of an unstable eddy. As in their simulations, the eddy loses mass along the slope (wall), creating an 
TABLE 1. Simulation parameters.

\begin{tabular}{|c|c|c|c|c|c|c|c|c|c|c|c|c|}
\hline & $\begin{array}{c}L \\
(\mathrm{~km})\end{array}$ & $\begin{array}{l}L^{z} \\
(\mathrm{~m})\end{array}$ & Ro & $\lambda$ & $\begin{array}{c}L_{\mathrm{sh}} \\
(\mathrm{km})\end{array}$ & $\begin{array}{c}L_{\mathrm{sl}} \\
(\mathrm{km})\end{array}$ & $S_{\mathrm{sh}}$ & $S_{\mathrm{sl}}$ & $\begin{array}{c}N^{2} \\
\left(1 \times 10^{-5} \mathrm{~s}^{-1}\right)\end{array}$ & $\begin{array}{c}f_{0} \\
\left(1 \times 10^{-5} \mathrm{~s}^{-1}\right)\end{array}$ & $\left(1 \times 10^{-11} \mathrm{~m}^{-1} \mathrm{~s}^{-1}\right)$ & $\left(1 \times 10^{-4} \mathrm{~m} \mathrm{~s}^{-1}\right)$ \\
\hline ew-05 & 41 & 292 & 0.18 & 0.18 & 40 & 50 & 0.00 & 1.50 & 1.0 & 5.0 & 6.0 & 0.0 \\
\hline ew-06 & 41 & 300 & 0.26 & 0.18 & 40 & 50 & 0.00 & 1.50 & 1.0 & 5.0 & 6.0 & 0.0 \\
\hline ew-34 & 38 & 344 & 0.10 & 0.15 & 40 & 50 & 0.00 & 1.50 & 1.0 & 5.0 & 1.5 & 0.0 \\
\hline ew-35 & 37 & 334 & 0.19 & 0.16 & 40 & 50 & 0.00 & 1.50 & 1.0 & 5.0 & 3.0 & 0.0 \\
\hline ew-36 & 36 & 321 & 0.27 & 0.16 & 40 & 50 & 0.00 & 1.50 & 1.0 & 5.0 & 5.0 & 0.0 \\
\hline ew-37 & 35 & 343 & 0.14 & 0.15 & 40 & 50 & 0.00 & 1.50 & 1.0 & 5.0 & 2.2 & 0.0 \\
\hline ew-6370 & 36 & 343 & 0.15 & 0.15 & 40 & 50 & 0.00 & 0.75 & 1.0 & 5.0 & 2.2 & 0.0 \\
\hline ew-2340 & 37 & 356 & 0.10 & 0.29 & 40 & 50 & 0.00 & 1.50 & 1.0 & 5.0 & 1.5 & 0.0 \\
\hline ew-2345 & 38 & 346 & 0.10 & 0.22 & 40 & 50 & 0.00 & 1.50 & 1.0 & 5.0 & 1.5 & 0.0 \\
\hline ew-2360 & 36 & 349 & 0.24 & 0.30 & 150 & 50 & 0.00 & 1.50 & 1.0 & 5.0 & 5.0 & 0.0 \\
\hline ew-2365 & 33 & 330 & 0.26 & 0.24 & 75 & 50 & 0.00 & 1.50 & 1.0 & 5.0 & 5.0 & 0.0 \\
\hline ew-23340 & 48 & 485 & 0.10 & 0.15 & 40 & 70 & 0.00 & 1.50 & 1.0 & 5.0 & 1.0 & 0.0 \\
\hline ew-24340 & 43 & 432 & 0.11 & 0.19 & 75 & 50 & 0.00 & 1.50 & 1.0 & 5.0 & 1.0 & 0.0 \\
\hline ew-4040 & 46 & 340 & 0.10 & 0.15 & 40 & 50 & 0.00 & 1.50 & 1.0 & 5.0 & 4.0 & 0.0 \\
\hline ew-4050 & 68 & 376 & 0.17 & 0.14 & 40 & 50 & 0.00 & 1.50 & 1.0 & 5.0 & 4.0 & 0.0 \\
\hline ew-4343 & 21 & 165 & 0.00 & 0.32 & 40 & 50 & 0.00 & 1.50 & 1.0 & 5.0 & 2.9 & 0.0 \\
\hline ew-5341 & 36 & 340 & 0.10 & 0.15 & 40 & 50 & 0.00 & 1.50 & 1.0 & 5.0 & 1.5 & 50 \\
\hline ew-5343 & 35 & 339 & 0.10 & 0.15 & 40 & 50 & 0.00 & 1.50 & 1.0 & 5.0 & 1.5 & 5.0 \\
\hline ew-5040 & 46 & 259 & 0.10 & 0.20 & 40 & 50 & 0.00 & 1.50 & 1.0 & 5.0 & 6.0 & 10 \\
\hline ew-5041 & 46 & 260 & 0.10 & 0.20 & 40 & 50 & 0.00 & 1.50 & 1.0 & 5.0 & 6.0 & 50 \\
\hline ew-5043 & 47 & 259 & 0.10 & 0.20 & 40 & 50 & 0.00 & 1.50 & 1.0 & 5.0 & 6.0 & 5.0 \\
\hline ew-8041 & 39 & 270 & 0.10 & 0.19 & 40 & 50 & 0.05 & 1.50 & 1.0 & 5.0 & 6.0 & 0.0 \\
\hline ew-8042 & 77 & 274 & 0.10 & 0.18 & 40 & 100 & 0.10 & 1.50 & 4.0 & 5.0 & 3.0 & 0.0 \\
\hline ew-8151 & 40 & 243 & 0.19 & 0.21 & 40 & 50 & 0.05 & 1.50 & 1.0 & 5.0 & 13 & 0.0 \\
\hline ew-8341 & 38 & 349 & 0.11 & 0.14 & 40 & 50 & 0.05 & 1.50 & 1.0 & 5.0 & 1.5 & 0.0 \\
\hline ew-8352 & 67 & 245 & 0.15 & 0.28 & 70 & 70 & 0.10 & 1.00 & 1.0 & 2.0 & 0.35 & 0.0 \\
\hline ew-8342-2 & 36 & 263 & 0.08 & 0.19 & 40 & 50 & 0.10 & 3.06 & 1.5 & 3.0 & 1.5 & 0.0 \\
\hline ew-8352-2 & 31 & 312 & 0.19 & 0.16 & 40 & 50 & 0.10 & 3.06 & 1.5 & 3.0 & 1.5 & 0.0 \\
\hline ew-583411 & 34 & 344 & 0.11 & 0.15 & 40 & 50 & 0.05 & 1.50 & 1.0 & 5.0 & 1.5 & 30 \\
\hline ew-583413 & 34 & 344 & 0.11 & 0.15 & 40 & 50 & 0.05 & 1.50 & 1.0 & 5.0 & 1.5 & 5.0 \\
\hline ew-8383 & 90 & 350 & 0.12 & 0.37 & 70 & 70 & 0.15 & 1.00 & 1.0 & 3.0 & 0.50 & 0.0 \\
\hline
\end{tabular}

alongshore jet moving away from the eddy, termed leakage by Shi and Nof (1993) and Pinnochio's nose intrusion by Zhang and Gawarkiewicz (2015). Oey and Zhang (2004) and Wei et al. (2008) observed similar along-slope or along-wall leakages in their modeling experiments, as did Chen et al. (2014) in their data assimilative solution. On encountering the slope, the eddy adjusts to the boundary condition by adopting an elliptical shape (termed wodon by Shi and Nof 1994). The eddy continually revolves elliptically, as observed by Vukovich and Waddell (1991). The advected shelfslope water parcels initially have a filamentlike structure (Fig. 2c). Later on, the shelf-slope water parcels form smaller-scale cyclones as they are advected around the eddy (Figs. 2d,e). There is an advective feedback from these cyclones back on to the main eddy. They make the track of the eddy's center "loopy" later in the run, when it is weaker after losing mass and energy to the leakage and Rossby wave radiation. Once the cyclone reaches the slope on the eastern side of the eddy, it combines with anticyclonic eddy water expelled from the edge of the eddy's core to form a dipole that propagates eastward away from the eddy (Fig. 2f). Not all of the expelled eddy water moves into the dipole. Instead, some eddy water propagates away from the eddy along the shelf break, forming small anticyclonic eddies. The cycle then repeats, with the main eddy becoming smaller and smaller. Observations indicate

TABLE 2. Terminology used in this paper.

\begin{tabular}{ll}
\hline \hline Term & \multicolumn{1}{c}{ Definition } \\
\hline$\left(L_{0}, L^{z}\right)$ & Gaussian horizontal and vertical scales of the eddy \\
$V_{0}$ & Maximum azimuthal velocity in eddy \\
$f_{0}$ & Coriolis frequency \\
$\beta$ & $d f / d y$ \\
$N^{2}$ & Buoyancy frequency \\
$\alpha_{\mathrm{sh}}, \alpha_{\mathrm{sl}}$ & Bottom slope magnitude of the shelf and slope \\
$S_{\mathrm{sh}}, S_{\mathrm{sl}}$ & $\alpha N / f_{0}$, shelf and slope Burger number \\
$H_{\mathrm{sb}}$ & Shelfbreak depth \\
$\lambda$ & $H_{\mathrm{sb}} / L^{z}$, nondimensional shelfbreak depth \\
$\mathrm{Ro}$ & $V_{0} /\left(f_{0} L_{0}\right)$, Rossby number \\
$r$ & Radial distance from eddy center \\
$r_{f}$ & Linear bottom drag coefficient $\left(\mathrm{m} \mathrm{s}{ }^{-1}\right)$ \\
$R$ & Distance of eddy center to shelf break \\
$y / R$ & Nondimensional isobath \\
\hline
\end{tabular}


that Gulf Stream warm-core rings decay as they move along-isobath but not to the point that they disappear (Olson et al. 1985). Instead, they are reabsorbed by the Gulf Stream.

In Fig. 2, the leakage propagates away from the eddy in the coastal-trapped wave direction (coast, or higher PV, to the wave's right) similar to the alongshore jet described in Chapman and Brink (1987). The agreement of directions is coincidental. Analogous simulations with a cyclone, moving northward on the $\beta$ plane toward shelfslope topography with a northern coast, show the leakage again moving eastward: opposite to the coastal-trapped wave direction but again away from the eddy (Nof 1988, 1999; Shi and Nof 1993). The leakage is caused by the eddy's circulation being interrupted by the slope or a vertical wall, a nonlinear interaction not represented by the linear wave physics of Chapman and Brink (1987).

\section{Diagnostics}

\section{a. Eddy diagnostics}

The eddy is tracked using the method described in Chelton et al. (2011) with slight modifications. The method detects a simply connected region within a closed SSH contour containing a SSH maximum (or minimum for a cyclone). The density anomaly value (with respect to background stratification) associated with the contour of maximum speed, or zero relative vorticity, within the detected region at $t=0$ is used to identify the eddy's core in three dimensions at all times. As will be shown, the 3D density anomaly surface successfully tracks dyed water that is transported in the eddy throughout the simulation. The eddy's center is defined as the location of the SSH maximum within the detected region.

The time series of the eddy's velocity and length scales are obtained by assuming that the eddy always remains a Gaussian density structure in all dimensions. At the surface, the density field is $\left\{\rho_{e} \exp \left[-\left(r / L_{0}\right)^{2}\right]\right\}$, with $r$ as the radial distance from the eddy's center. The corresponding balanced geostrophic velocity field, with maximum velocity $V_{0}$, is described by

$$
V=(\sqrt{2 e}) V_{0}\left(\frac{r}{L_{0}}\right) e^{-\left(r / L_{0}\right)^{2}}
$$

Equation (8) is fit to the eddy's surface velocity along a horizontal line in the along-isobath direction. The fit determines the eddy's maximum azimuthal velocity $V_{0}$ and its Gaussian length scale $L_{0}$ at the latitude of the eddy's center. These metrics, though based on approximations about eddy shape, are much less sensitive than estimating average velocities along an identified contour or the contour's equivalent radius. A Gaussian fit $\exp \left[-\left(z / L^{z}\right)^{2}\right]$ to the vertical profile of the temperature anomaly at the eddy's center diagnoses its vertical scale $L^{z}$. The eddy's Rossby number is defined as $\operatorname{Ro}(t)=V_{0}(t) /\left[f_{0} L_{0}(t)\right]$.

\section{b. Calculating fluxes}

The instantaneous offshore flux is calculated as the integral of the cross-isobath velocity over the area containing water parcels that were initially inshore of the isobath: that is, the advected water parcels that have a cross-shelf dye value smaller than the ambient water at that isobath. In the vertical, we integrate between shelfbreak depth and the surface. In the horizontal, the integration region is between the edge of the western sponge layer and the eddy's center with one exception. At the shelf break, we choose to integrate between the two sponge layers (justified in section 7 and Fig. 15).

The time series of instantaneous flux for the simulation in Fig. 2 is shown in Fig. 3 (red solid line). There is a ramp-up period as the eddy gets to the shelf break and later a slow decrease in magnitude as the eddy translates alongshore. The decrease is caused by the eddy slowly decaying as it loses mass to the leakage and energy to radiated waves (Flierl et al. 1983). The peaks and troughs in the time series are due to the secondary cyclones moving the eddy toward and then away from the shelf break.

We seek to calculate an average flux across the isobath over a time interval that does not contain the ramp-up and decay phases. For this, we use the cumulative time integral of instantaneous flux: the total volume transported across the isobath up until that time (Fig. 3, solid orange line). We choose the time interval $\left[t_{\text {start }}, t_{\text {stop }}\right]$, where $t_{\text {start }}$ is the time at which the cumulative volume transported is $5 \%$ of the total, and $t_{\text {stop }}$ is the time at which $90 \%$ of the total volume has been transported across the isobath. These thresholds were chosen to maximize the length of the averaging time period while avoiding the ramp-up and decay phases. The average flux is calculated as the mean of the instantaneous flux in this time interval. The number of degrees of freedom is approximated by dividing the number of samples in $\left[t_{\text {start }}, t_{\text {stop }}\right]$ by an integral time-scale estimate. The latter is the maximum time scale obtained by integrating the autocorrelation of the flux time series over successively larger lags (Talley et al. 2011). The vertical extent of the shaded region indicates the $95 \%$ confidence interval on the average flux estimate. Its horizontal extent shows the time interval $\left[t_{\text {start }}, t_{\text {stop }}\right]$ over which the average is estimated.

A nondimensional isobath location is used to compare flux estimates across different runs. It is defined as the ratio of $y$, the distance from the shelf break to the isobath, to $R$, the distance from the shelf break to the eddy center (Fig. 4). 


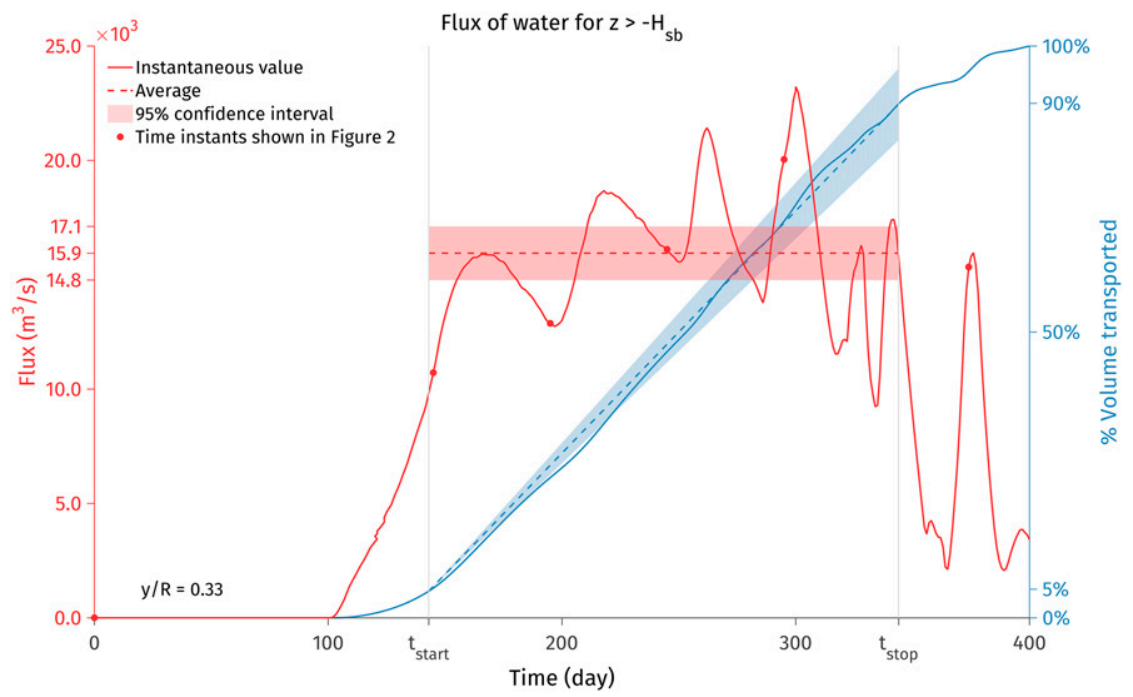

FIG. 3. Flux diagnostics used in this paper. The red solid line is a time series of the instantaneous offshore flux above $z=-H_{\mathrm{sb}}$ of water that originated inshore of nondimensional isobath $y / R=1 / 3$, calculated at that isobath for the simulation in Fig. 2. The blue solid line is the cumulative integral of this flux: the time series of the volume transported across that isobath. The average flux (dashed line) is calculated for the time interval starting when $5 \%$ of the total volume has been transported $t_{\text {start }}$ and ending when $90 \%$ of total volume has been transported $t_{\text {stop. }}$. The interval $\left[t_{\text {start }}, t_{\text {stop }}\right]$ is indicated by the horizontal extent of the shaded regions. The vertical extent of the shading shows $95 \%$ confidence bounds. Red dots indicate time instants of the snapshots in Fig. 2.

\section{c. Resolution dependence}

Experiments using a uniform 750-m grid compare favorably with those using a uniform 1-km grid. There are very slight differences in the track of the eddy. The average flux diagnostic differs only by $5 \%$, and the maximum flux increases by $15 \%$. Runs with and without horizontal grid stretching showed no difference in the diagnostics.

\section{Streamer flow over the slope}

\section{a. The mean streamer field}

We begin with a picture, Fig. 5, of the cross-isobath flow field experienced by shelf-slope water that originated inshore of isobath $y / R=1 / 2$. It is representative of many simulations and all isobaths offshore of the shelf break. The color panel shows the time-averaged, cross-isobath
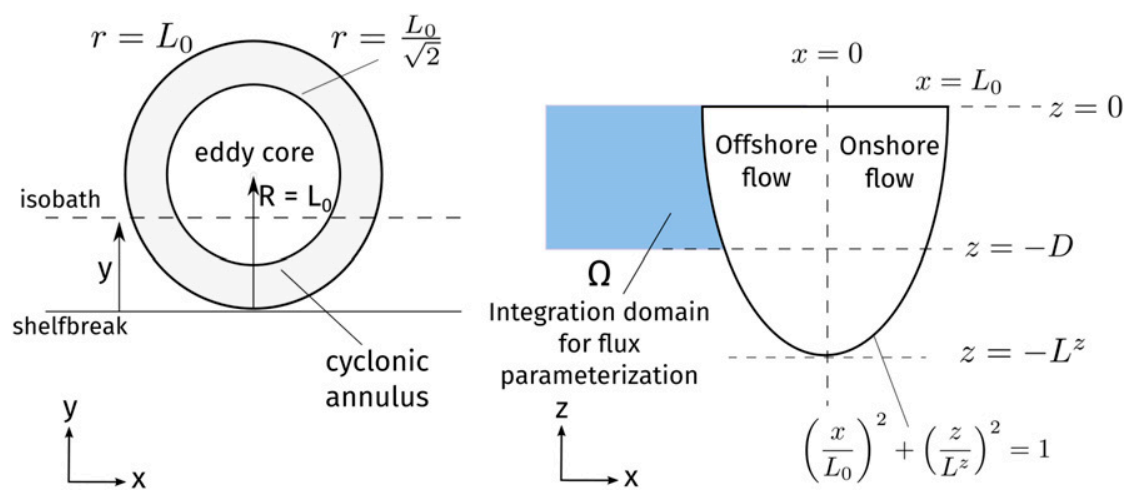

FIG. 4. Schematics showing how the dye field is reconstructed to obtain a prediction for flux magnitude. (left) An idealized representation of the eddy as two concentric contours: the inner one is the radius to maximum velocity $r=L_{0} / \sqrt{2}$, and the outer is $r=L_{0}$. The variables $y, R$ are used to define a nondimensional isobath value (section $4 \mathrm{~b}$ ), the flux across which will be compared across all runs. (right) In blue, the domain over which an idealized velocity field is integrated. 

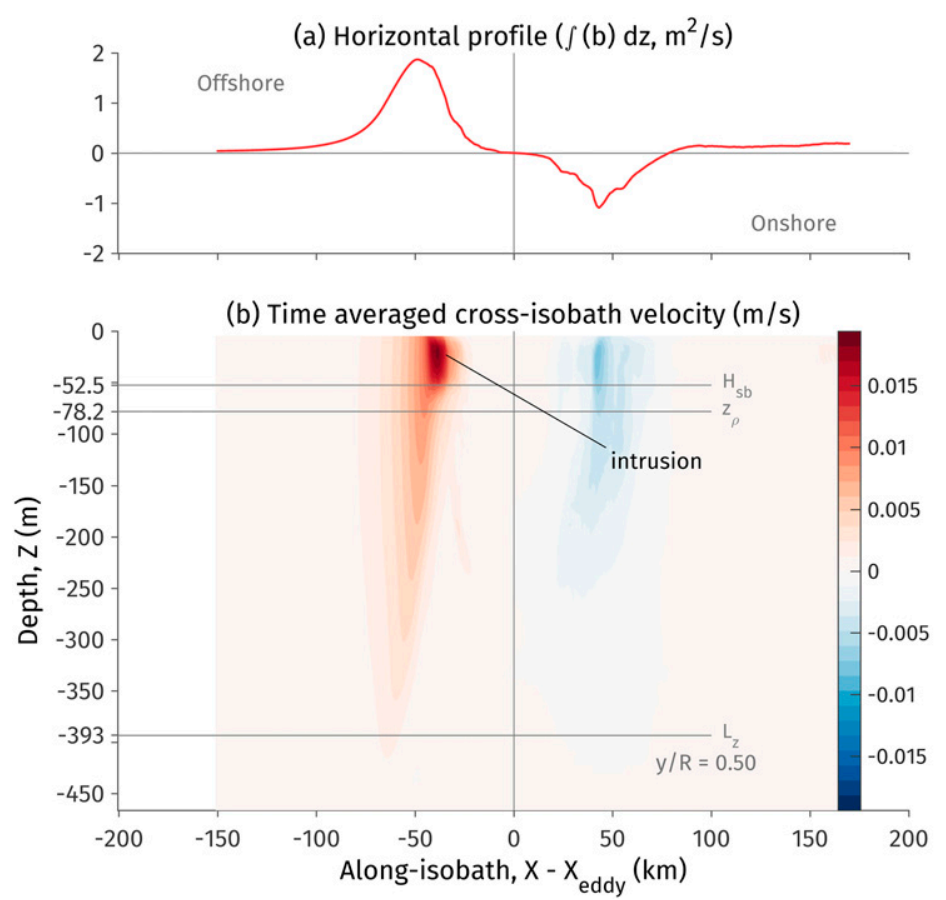

(c) Vertical profile of offshore transport

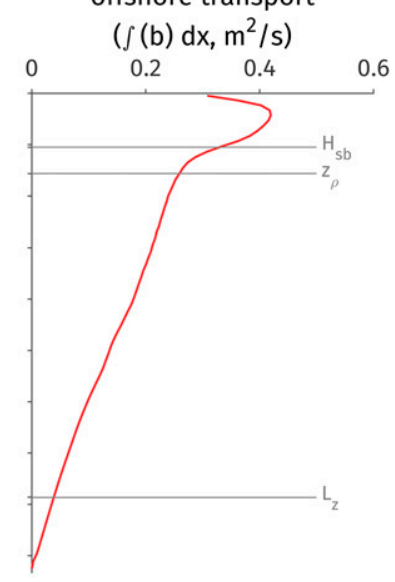

FIG. 5. Averaged cross-isobath velocity field integrated to show both along-isobath and vertical structure for ew-34. The instantaneous snapshots of cross-isobath velocity are averaged together in a reference frame with the eddy's center as origin. The average is over $\left[t_{\mathrm{start}}, t_{\mathrm{stop}}\right]$ (section $4 \mathrm{~b}$ ); $z_{\rho}$ is the predicted depth of the intrusion (section $9 \mathrm{a}$ ).

velocity field, experienced by shelf-slope water, in a reference frame moving with the eddy whose center is at $x=0$. It is constructed using two pieces of information: 1) at each time step, the instantaneous cross-isobath velocity field is interpolated to a coordinate system with the eddy's current center location as origin; and 2) using the cross-shelf dye, we construct a mask identifying water parcels that started inshore of the chosen isobath, that is, the parcel's initial location $=$ cross-shelf dye value $<$ isobath location. We then average the product of these two fields over $\left[t_{\text {start }}, t_{\text {stop }}\right]$ defined in section $4 \mathrm{~b}$. The other two panels in Fig. 5 show the along-isobath and vertical profile of the offshore flow obtained by integrating the averaged field (color panel) in $z$ and $x$ (up to eddy center, $x=0$ ), respectively.

The peak in onshore flow is smaller: there is net offshore export across this isobath. To the east of the eddy, the shelf-slope water mass is transported out the eastern boundary during the eddy's initial approach (Fig. 2c), whereas to the west, the shelf-slope water mass is relatively undisturbed. Consequently, the water mass volume is permanently reduced on the east side, whereas to the west, the undisturbed dye field is potentially an infinite source of the water mass. Additionally, some western water parcels mix as they move around the eddy, losing their identity by the time they reach the isobath of interest on the eastern side. Thus, larger offshore transport is accomplished during the simulation.
The along-isobath structure is as expected: there is a peak in offshore flow that decays away from the eddy (Fig. 5). The vertical structure is surprising: there is a pronounced subsurface peak in the offshore flow of shelf-slope water. The total instantaneous velocity field is always surface intensified (see Fig. 6), as expected since the eddy is initialized to be surface intensified. The black contour in Fig. 6 is the mask. It bounds the region containing shelf-slope water that started inshore of the isobath, that is, the region over which we integrate the velocity field to obtain the instantaneous cross-isobath transport. The subsurface peak reflects an intrusion into the eddy, a kink in the black contour, at $z \approx-30 \mathrm{~m}$. The peak is a result of the larger horizontal extent of the integration domain at $z \approx-30 \mathrm{~m}$ and nearby depths. The peak is robust and exists for all runs conducted with anticyclonic eddies, so a general mechanism is at play.

\section{b. The intrusion mechanism and the creation of dipoles}

Why is there a subsurface maximum in offshore transport, associated with an apparent intrusion of shelf water into the eddy? The gist is that the shelf-slope water does not intrude into the eddy. Instead, the eddy bulges out below shelfbreak depth for two reasons:

(i) below shelfbreak depth, the eddy adjusts to the boundary condition imposed by the slope by 
(a) Cross-isobath velocity $(\mathrm{m} / \mathrm{s})$

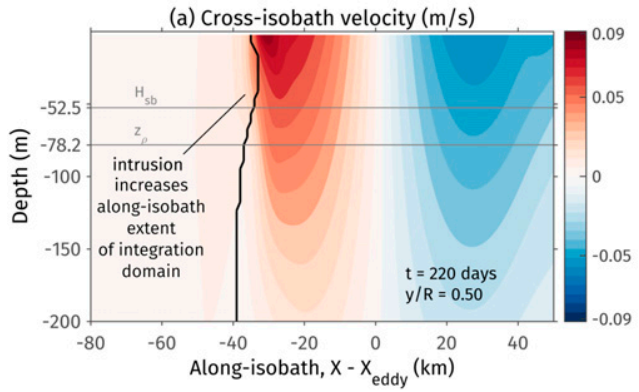

(c) $\rho$ contours

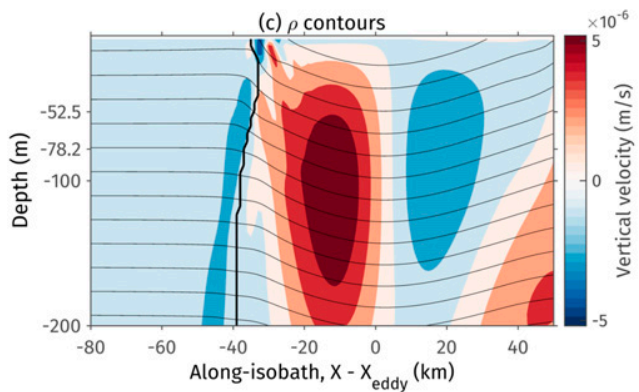

(b) Vertical profile of offshore transport $\left(\mathrm{m}^{2} / \mathrm{s}\right)$
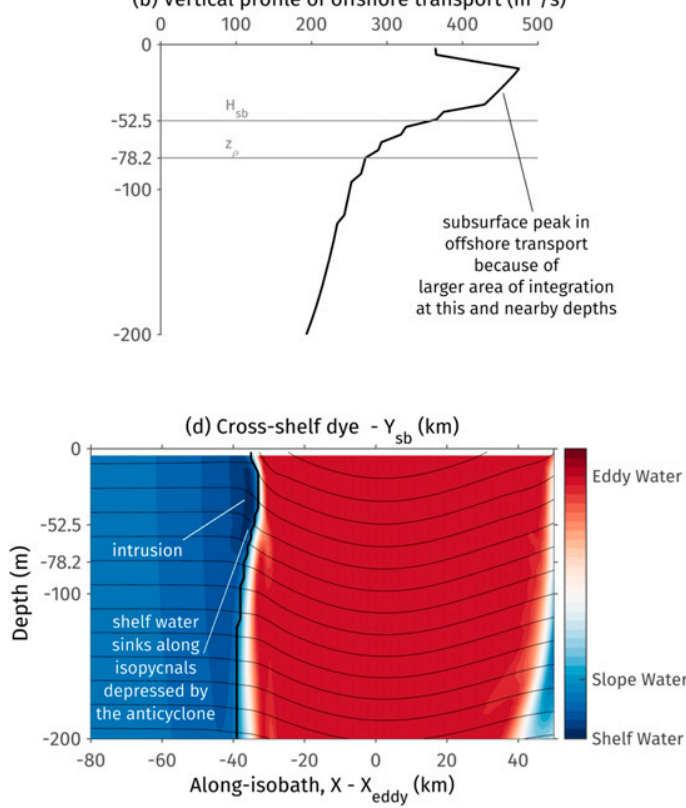

FIG. 6. Instantaneous $x-z$ sections for ew-34. (a) Surface-intensified cross-isobath velocity field and an intrusion into the eddy. The black contour is the boundary between eddy and shelf-slope water. Integrating the cross-shelf velocity field (a) within the black contour in $x$ results in (b) the vertical profile of offshore transport with a subsurface peak. The shape of the integration region is solely responsible for the peak. (c) Downward velocities experienced by slope-water parcels as they sink along isopycnals to a depth $z_{\rho}$ (section 6). (d) The cross-shelf dye field, with overlaid $\rho$ contours.

compressing itself in the cross-isobath direction and squeezing out in the along-shelf direction (Shi and Nof 1994); and

(ii) a cyclonic vorticity anomaly propagating on the eddy's PV gradient appears as an additional propagating bulge on the eddy's side.

Near the surface, the eddy advects shelf-slope water over the bulge in its deep structure, making it appear as if shelf-slope water is intruding into the eddy (Fig. 6).

The formation of apparent intrusions and eventually dipoles is described using two figures. Figure 7 shows $x-y$ slices of the eddy dye field (in red) at $z=-75 \mathrm{~m}=1.5 \times$ $H_{\mathrm{sb}}$. The blue contour indicates the location of a single value of cross-shelf dye at the surface, and the green contour identifies the core of the eddy defined using a density anomaly criterion, again, at the surface (section 4). Figure 8 shows a three-dimensional summary of the process again using passive tracers; the red surface identifies the edge of the eddy and the blue surface visualizes shelf-slope water. Following Shi and Nof (1993), it is useful to idealize the eddy as two concentric contours-one being the radius to maximum velocity containing the anticyclonic core of the eddy and the other indicating the boundary of the eddy fluid (Fig. 4). Between the two contours lies an annular region of cyclonic relative vorticity where the velocity of the eddy decays from its maximum value to nearly zero. For the idealized Gaussian eddy as defined in (6), these contours are $r=1 / \sqrt{2}$ and roughly $r=1$.

The sequence of events is as follows:

1) As the eddy approaches from the north, the slope interrupts its circulation below shelfbreak depth by imposing a no-normal flow boundary condition.

(i) Because the slope is steep compared to the eddy, this is effectively a lateral boundary condition on the eddy. Above shelfbreak depth, there is no such imposition. The difference is key: below shelfbreak depth, the eddy responds as described in Shi and Nof (1994) by bulging out and adopting a more elliptical shape (Fig. 8c).

(ii) Below shelfbreak depth, the slope also diverts some eddy water alongshore, away from the eddy. This can be visualized as a nonlinear jet of water splitting into two upon hitting a wall (Oey and Zhang 2004; Whitehead 1985). Above shelfbreak depth, where there is no boundary, some eddy water spills onto the shelf and spreads alongshore away from the eddy. The water currently in the leakage is lost from the eddy's cyclonic annulus-the gap 


\section{Eddy dye at $z=-75 \mathrm{~m}\left|\mathrm{H}_{\mathrm{sb}}=50 \mathrm{~m}\right| \mathrm{Ro}=0.10$}
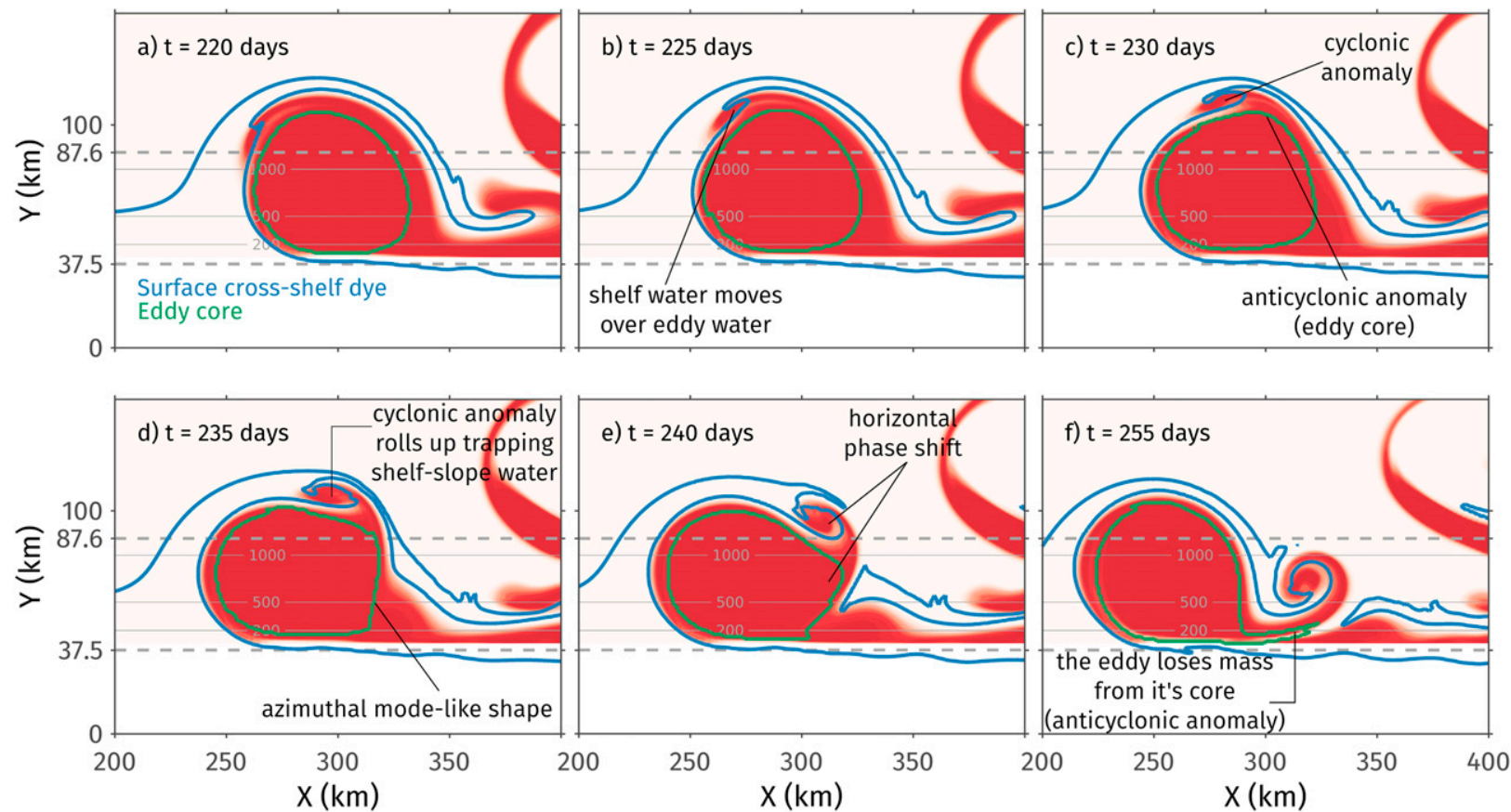

FIG. 7. Growth of unstable anomalies shown by snapshots of eddy dye field interpolated to $z=-75 \mathrm{~m}$ (ew-34). The shelfbreak depth is $50 \mathrm{~m}$ and the eddy's vertical scale is $400 \mathrm{~m}$. Bathymetric contours are in gray, with dashed lines indicating the shelf and slope break. All other contours are of surface fields. The cross-shelf dye is in blue, showing offshore transport of slope water. The green contour defines an eddy core at the surface. (a),(b) The slope water, advected by the near-surface velocity field, intrudes into the eddy (blue contour moves over red dye). (c),(d) The cyclonic annulus fluid at depth starts to roll up into a cyclonic vortex trapping the shelf-slope water above it. (e) The cyclonic vortex is nearly fully formed with shelf water on top (nearly closed blue contour) and eddy water below (red). The phase difference between cyclonic and anticyclonic anomalies is apparent. (f) The eddy flings the cyclone away, which extracts some eddy water from the core (elongated green contour). The two pieces combine to form a dipole later.

between the green and blue contours in Fig. 7-as in Shi and Nof (1993) and Zhang and Gawarkiewicz (2015).

2) The eddy advects shelf-slope water parcels over the bulge that exists in its structure below shelfbreak depth (blue filament in Fig. 8c). The advected shelfslope water (blue contour in Fig. 7) takes the place of the eddy's lost annulus fluid. In the cross section, it appears as if the shelf-slope water is intruding into the eddy (Fig. 8c).

3) Simultaneously, at depth, to the west of the eddy center, cyclonic vorticity is generated at the slope. This may happen for two reasons. First, bottom friction at the slope (if present) generates cyclonic vorticity by retarding the along-isobath velocity. Second, hydraulic arrest of topographic waves by the eddy's flow can create vorticity of sign opposite that of the main eddy (Dewar et al. 2011).

4) Propagating vorticity anomalies, both cyclonic and anticyclonic, are now excited on the PV gradient of the eddy. They are identified as such following Shi and Nof (1993), who show a cyclonic anomaly propagating on the outer PV contour and an anticyclonic anomaly propagating on the inner contour (Shi and Nof 1993, their Fig. 3). These anomalies are likely a result of the slope interrupting the circulation of the baroclinically unstable eddy and perturbations due to the cyclonic vorticity being generated at the slope. The anomalies are seen in Figs. 7c-e as a bulge in the red eddy dye field at the outer edge of the eddy (cyclonic) and in the azimuthal modelike shapes seen in the eddy core (anticyclonic, green contour).

5) The apparent intrusion highlighted in Fig. 6 is a result of the shelf-slope water being advected over the bulge in the eddy's shape below the shelfbreak depth (Fig. 8). The fate of the shelf water is now tied to that of the cyclonic anomaly.

6) The vorticity anomalies phase lock, mutually amplify, and ultimately grow to finite amplitude as they propagate around the eddy, as in Shi and Nof (1993). The peaks in the cross-isobath flux time series in Fig. 3 correspond to the cyclonic anomaly crossing that isobath. Unambiguously determining the nature of the instability is difficult. There is a horizontal 


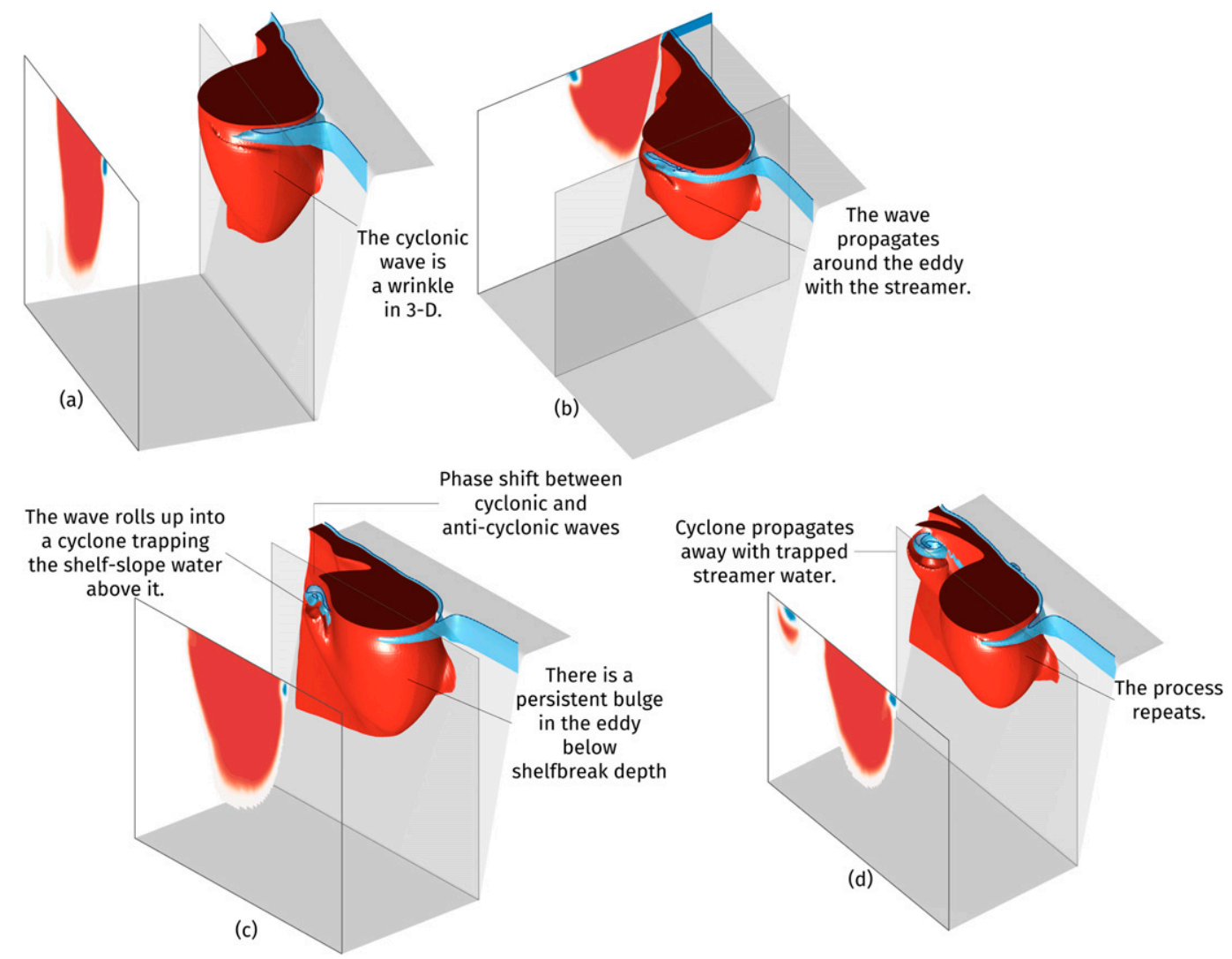

FIG. 8. Smoothed dye fields at $t=215,225,235$, and 255 days for the same simulation (ew-34), as in Fig. 7.

phase shift between two anomalies (Figs. 7e, 8c). The eddy and shelf-slope water filament might be undergoing a barotropic instability as in Shi and Nof (1993). However, if one were to consider eddy water alone, the cyclonic anomaly only exists below shelfbreak depth, while the anticyclonic anomaly is visible at the surface-there is some baroclinic character to the evolution.

7) As the cyclonic anomaly amplifies and rolls up into a vortex at depth, it traps the shelf-slope water above it (Fig. 8). The cyclonic anomaly now has a stacked vertical structure that is preserved through the rest of its evolution. Below shelfbreak depth (roughly), the water column contains eddy water, while above it, there is shelf-slope water that has taken the place of the shed annulus fluid (Figs. 7d-f, 9; section 9a).

8) When the phase-locked finite amplitude anomalies reach the slope on the eastern side of the eddy, they break off as a dipolar chunk of water (Fig. 7f). The cyclonic anomaly is now a vortex, whereas the anticyclonic anomaly is expelled from the eddy's core as a filament of fluid. The two then eventually form a dipole that propagates away. Not all of the eddy water expelled from the main eddy is in the dipole; some of it is deposited at the shelf break where it then forms small, surface-intensified anticyclonic eddies that translate along the shelf break (Figs. 2d-f).

9) This process repeats itself, with the eddy continually losing mass. The eddy is ultimately destroyed if the model is integrated for long enough.

Even though the eddy is always surface intensified, the vertical profile of average cross-isobath transport always has a subsurface maximum (Figs. 5, 6). The maximum is a result of the larger horizontal extent of the integration region where shelf water appears to intrude into the eddy (Fig. 6). We have argued that the shelf-slope water is not intruding into the eddy; instead, it is advected over a bulge in the eddy's shape below shelfbreak depth. The bulge exists for two reasons: the eddy adjusts to the boundary condition imposed by the continental slope, and cyclonic anomalies propagate on the eddy's PV gradient (Figs. 8a,c). The propagating cyclonic anomaly traps near-surface, shelf-slope water as it rolls up into a cyclone (Figs. 8c,d). Finally, the stacked cyclone forms a dipole 


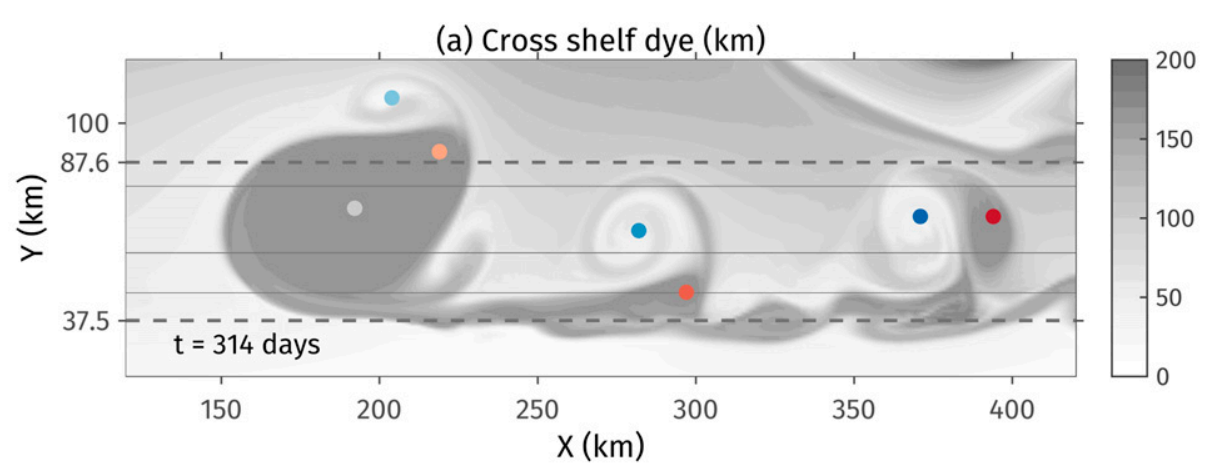

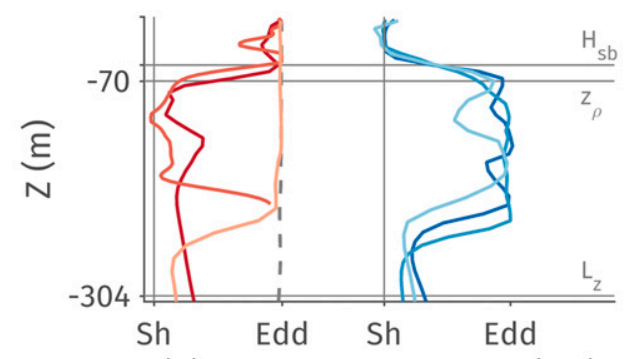

(b) Cross-shelf dye $-X_{\text {sb }}(\mathrm{km})$

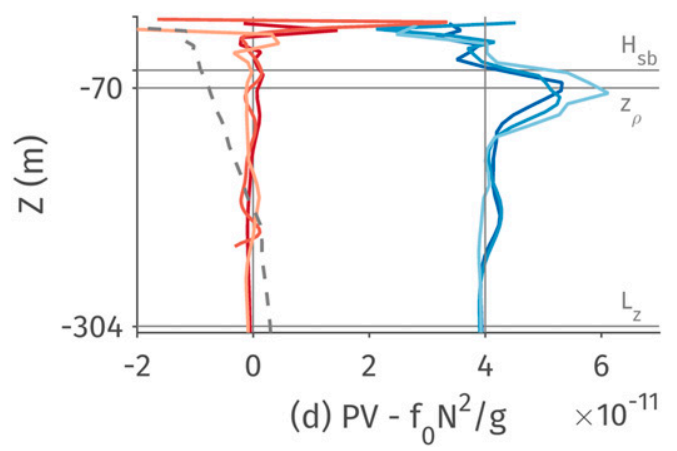

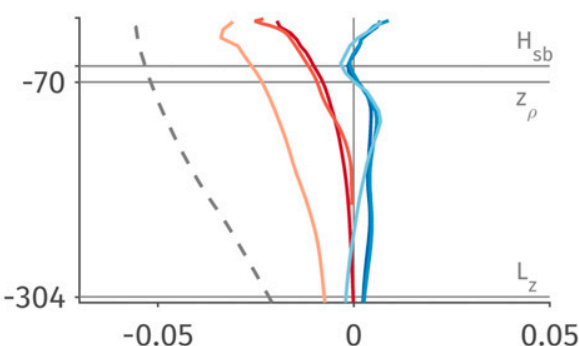

(c) $\Delta \rho\left(\mathrm{kg} / \mathrm{m}^{3}\right)$

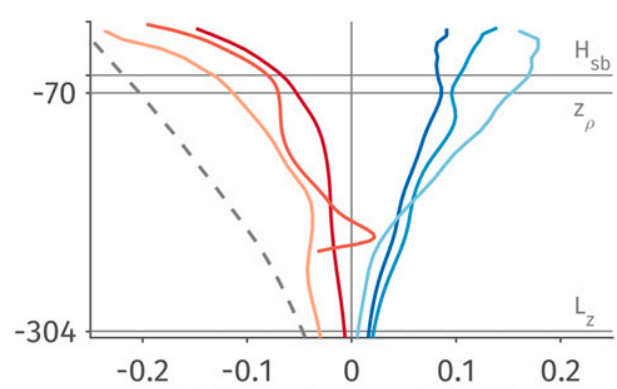

(e) (Relative vorticity)/f 0

FIG. 9. (a) Surface map of cross-shelf dye for simulation ew-34. (b)-(e) Vertical profiles at the dots marked in (a), illustrating the transition from an unstable anomaly to a dipole for simulation ew-34. The red profiles, on the left in each panel, are in locations with anticyclonic vorticity and vice versa. The gray dashed profile is at the eddy center providing a reference value for the fields. (b),(d) The lines on the right are displaced to make them easier to see; $z_{\rho}$ is the predicted depth to which shelf water sinks, determined using the initial density field (see text). In (b), water masses as identified by cross-shelf dye: Sh is shelf-slope water and Edd is eddy water. (c) Profiles of the density anomaly. The anticyclones are always lighter than ambient water. The cyclones have the stacked structure explained in section 6. In (d), profiles of PV anomaly are shown; the cyclones have a subsurface peak corresponding to the interface between shelf and eddy water. (e) Normalized relative vorticity whose sign does not change with depth.

with water expelled from the eddy's core. The process is dissipative in that it acts to transfer energy from the main eddy to smaller-scale features.

\section{The fate of streamer water}

The shelf-slope water is permanently exported in dipoles that propagate eastward away from the eddy, that is, downstream in the coastal-trapped wave, or Kelvin wave, sense. The dipoles then interact with the leakage and other flow features that have not escaped the domain. Vertical profiles of cross-shelf dye at different stages in the formation of the dipole show that the cyclone's stacked structure is preserved throughout (Fig. 9b). The boundary between the two water masses in the cyclone is the depth $z_{\rho}$ of the isopycnal surface of same density as the densest shelf water. The shelf water stretches and sinks to this surface as it moves offshore (Fig. 6d). The eddy water upwells from depth so that the isopycnals pinch 


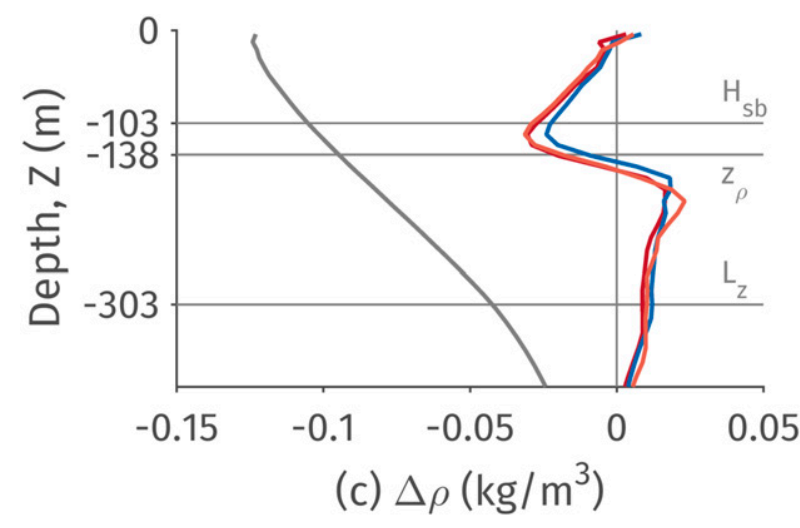

FIG. 10. Vertical profiles of density anomaly with respect to background stratification through the secondary cyclone for a simulation with shelfbreak depth of $100 \mathrm{~m}$ (ew-2360). Colored profiles are at three different locations in the secondary cyclone and the gray profile is at the eddy center ( $\Delta \rho$ is always negative). The density anomaly is negative above shelfbreak depth, indicating stretching and sinking of shelf water. Below it is positive, indicating upwelling and rising of denser eddy water from depth.

together at $z_{\rho}$, associated with a subsurface peak in PV (Fig. 9d). The depth $z_{\rho}$, marked in Fig. 9, is determined by comparing the initial density profile on the shelf to that one eddy radius away from the eddy center. It is also the width of the peak in offshore transport and the depth of the apparent shelf-slope water intrusion in Figs. $6 b$ and 5.

The sinking of shelf-slope water along isopycnals creates negative density anomalies in the cyclones around $H_{\mathrm{sb}}$ (Fig. 9c). Closer to the surface, the density signal is complicated by the surface boundary layer forced by the no-flux condition on temperature at the surface. This particular run is long enough that the boundary layer depth reaches $30 \mathrm{~m}$ with background vertical mixing. Figure 10 shows vertical profiles at $t=$ 79 days for three locations through the secondary cyclone for a different run with a shelfbreak depth of $100 \mathrm{~m}$. The density anomaly profile, relative to $H_{\mathrm{sb}}$, is similar to that in Fig. 9c, indicating upwelling of deep eddy water (denser than ambient) and sinking/ stretching of shelf water (lighter than ambient).

In the dipole, the anticyclonic vortex is stacked too; it contains eddy water to roughly shelfbreak depth and shelf-slope water underneath (reddish-orange profiles in Fig. 9a). The shelf-slope water appears to be trapped after the anticyclone is expelled from the eddy core. The density anomaly in the anticyclonic anomaly is not as negative as at the eddy's center because the eddy expels fluid from its annular edge (Shi and Nof 1993; Zhang and Gawarkiewicz 2015). Despite the complex water mass structure, relative vorticity does not change sign with depth for all profiles in Fig. 9e.

\section{Flow at the shelf break}

At the shelf break, the offshore flow structure is less complicated-it is barotropic and occurs on both sides of the eddy center (Fig. 11) even with bottom friction. As the eddy's horizontal scale is much larger than the shelf's internal deformation radius, the forcing at the shelf break is barotropic, and it drives a barotropic export of shelf water. An along-shelf flow over the entire shelf supplies the outflow (Fig. 12). With a sloping shelf, there is a limit to the extent of the eddy's influence on the shelf. This will be addressed in a future paper. That export occurs even to the east of the eddy's center $(x-$ $x_{\text {eddy }}>0$ in Fig. 11) can be explained as follows.

When the eddy reaches the shelf break, on the eastern side and below shelfbreak depth, the slope diverts some of the eddy's incoming flow to the east-the leakage. Above the shelf break, some of the eddy's flow is also diverted, but this fluid can return to the main eddy while spilling onto the shelf (Fig. 12, top panel, $x=250 \mathrm{~km}$ ). The leaked eddy water raises the SSH at the shelf break. There is then a SSH gradient in both along-shelf and cross-shelf directions, forcing both an along-shelf westward flow on the shelf and a cross-shelfbreak offshore flow to the east of the eddy center (Fig. 12). Eventually, the leaked eddy water breaks off and propagates along shelf away from the main eddy. The cycle then repeats.

When the dipole is formed, it does not comprise all of the water expelled from the eddy core. Some eddy water is deposited at the shelf break, while the dipole moves northward away from the shelf break (Fig. 12, top panel, $x=350 \mathrm{~km}$ ). Farther downstream, away from the eddy (Kelvin or coastal-trapped wave sense), the leaked water rolls up into small, surface-intensified anticyclonic vortices at the shelf break (Fig. 12 at $x=350$ and $400 \mathrm{~km}$; Fig. 2e at $x \approx 400 \mathrm{~km}$ ). These vortices transport shelf water both onshore and offshore near the bottom while translating along the shelf break away from the eddy. The offshoreonshore transport is seen far away from the eddy center in the lower panels of Fig. 15 (shown below). There is very little sign of it in the average cross-isobath velocity field (Fig. 11). So integrating over the entire length of the shelf break to estimate a flux magnitude is not a bad choice because the small-scale vortices accomplish little net transport.

\section{Flux parameterization}

We now develop a parameterization to predict the average offshore transport between $\left[t_{\mathrm{star}}, t_{\mathrm{stop}}\right]$ to be used with satellite data for estimates of real-world transports. The water mass of interest here comprises parcels that originate onshore of a specified isobath. We make four assumptions: 

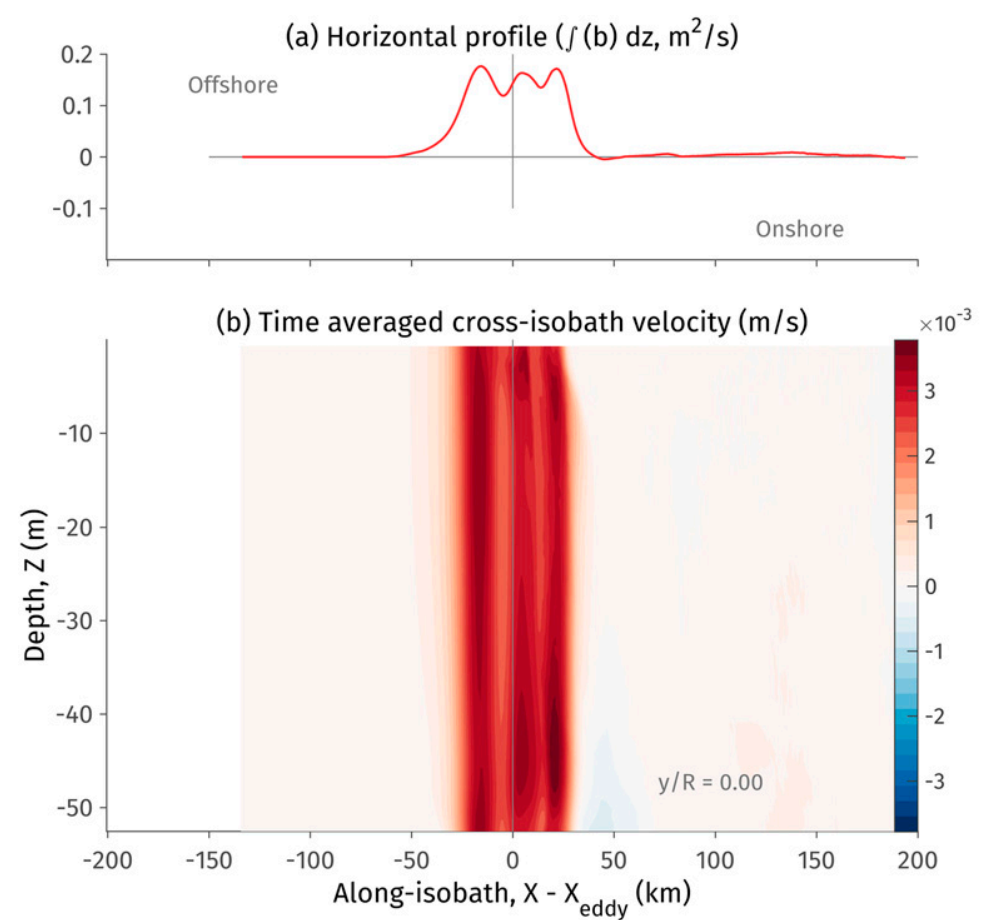

(c) Vertical profile of offshore transport ( $\left(\right.$ (b) $\left.\mathrm{dx}, \mathrm{m}^{2} / \mathrm{s}\right)$

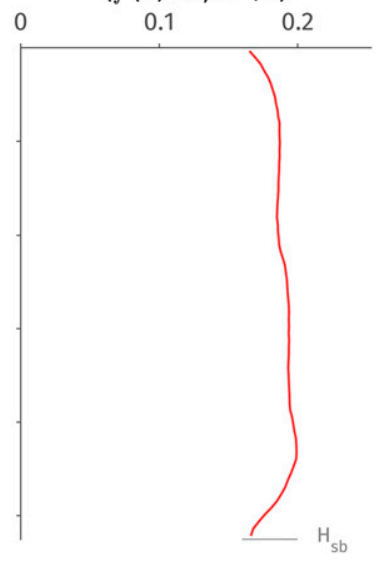

FIG. 11. (b) Averaged cross-isobath velocity field integrated to show both (a) along-isobath and (c) vertical structure at the shelf break for a flat shelf (ew-34). To obtain this image, instantaneous snapshots of crossisobath velocity are averaged together in a reference frame based on the eddy's center as origin. The average is over the time interval $\left[t_{\text {start }}, t_{\text {stop }}\right]$ (section $4 \mathrm{~b}$ ). There is offshore transport both to the east and west of the eddy's center; its vertical structure is barotropic.

(i) The eddy's structure is well approximated by a Gaussian density anomaly in $(x, z)$, with $x$ being the along-isobath direction. In $y$, generally cross isobath, the eddy's structure is complicated by the eddy adjusting to the slope; its form is determined later by regression.

(ii) Thermal wind balance is an accurate estimate of the vertical structure of the cross-shelf velocity field.

(iii) The eddy's core is bounded by the contour $\left(x / L_{0}\right)^{2}+$ $\left(z / L^{z}\right)^{2}=1$.

(iv) The eddy's center is always a radius away from the shelf break, radius being the Gaussian length scale $L_{0}$ (section 4a), so that $R=L_{0}$ in Fig. 4. We ignore loopiness in the eddy tracks.

Our approach is to approximate velocity and dye fields similar to Fig. 5 and integrate over them numerically. The steps are as follows ${ }^{3}$ :

1) Determine the eddy scales $V_{0}, L_{0}$, and $L^{z}$ when the eddy is at the shelf break (defined in section 4a). The

\footnotetext{
${ }^{3}$ A MATLAB script that implements this algorithm is available at https://github.com/dcherian/eddyshelf/blob/master/PredictFlux.m.
}

time series of eddy scales can be noisy, particularly in $\left[t_{\text {start }}, t_{\text {stop }}\right]$. So, we choose to use the time average of $V_{0}, L_{0}$, and $L^{z}$ over $t=\left[0, t_{\text {start }}\right]$.

2) Assuming that the eddy always remains Gaussian in the along-isobath plane, reconstruct the crossisobath velocity field $V$ at $y=y_{0}$ using thermal wind balance (assumptions i and ii):

$$
\begin{aligned}
V\left(x, y_{0}, z\right)= & (\sqrt{2 e}) V_{0} Y_{v}\left(y_{0}\right) \frac{x}{L_{0}} e^{-\left(x / L_{0}\right)^{2}} \\
& \times\left[1-\operatorname{erf}\left(-\frac{z}{L^{z}}\right)\right] .
\end{aligned}
$$

The eddy's center is at $(x, y)=(0,0)$. If the eddy was Gaussian in $y, Y_{v}=e^{-\left(y_{0} / L_{0}\right)^{2}}$. However, the crossisobath structure of the velocity field is modified by the eddy being squeezed against the slope and spilling onto the shelf. We obtain the best results by not assuming the Gaussian form for $Y_{v}$, which is left undetermined for now.

3) Construct a region $\Omega$ over which to integrate the assumed velocity field: the blue region in Fig. 4 . In the vertical, integrate from the desired depth, $z=-D$, to the surface. Further, assume that shelf water is only present outside the eddy's core and integrate over 


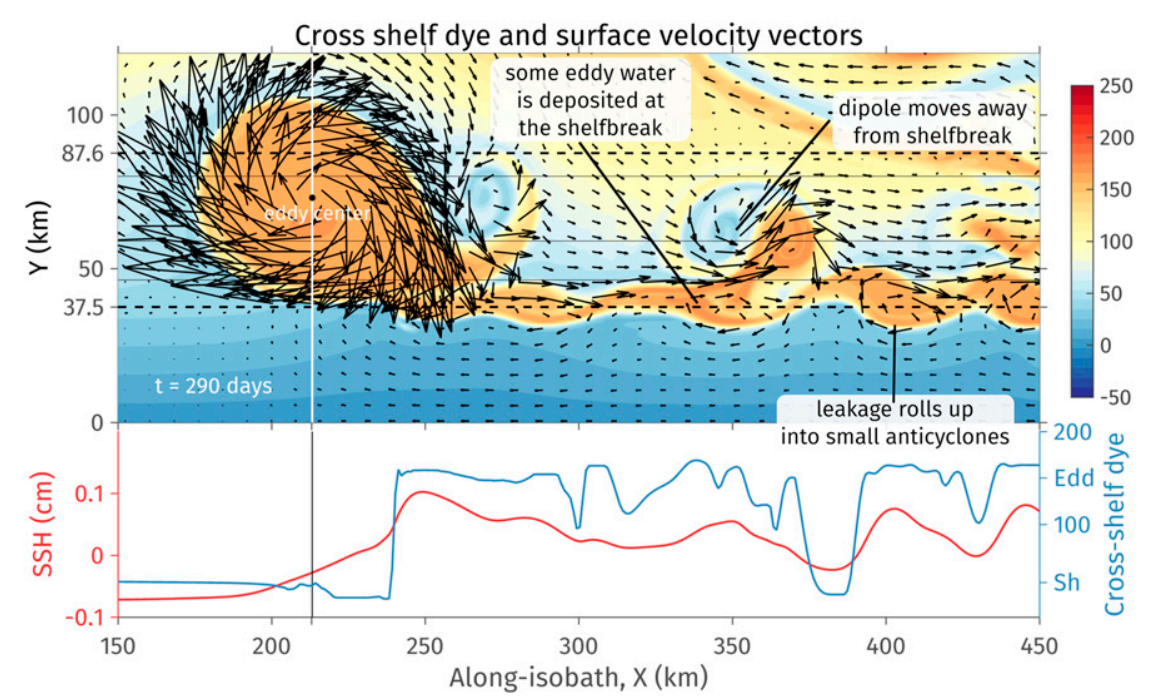

FIG. 12. (top) Horizontal velocity vectors and cross-shelf dye at the surface for a flat shelf (ew-34). (bottom) Along-shelf profiles of SSH and cross-shelf dye at the shelf break. There is offshore transport to the east of the eddy's center driven by eddy water leaking on to the shelf. All of the shelf to the east of the eddy is forced into motion to supply the offshore flow. For $x \lesssim 180 \mathrm{~km}$, shelf velocities are negligible.

$\left(x / L_{0}\right)^{2}+\left(z / L^{z}\right)^{2} \geq 1$ (assumption iii). Accounting for the intrusion in the eddy's side (Fig. 6) does not improve the estimate. The region $\Omega$ is the set

$\Omega=\left\{(x, z) \mid-D \leq z \leq 0,\left(x / L_{0}\right)^{2}+\left(z / L^{z}\right)^{2} \geq 1\right\}$.

4) Numerically integrate the assumed velocity field over $\Omega$ to get a transport estimate $T$ :

$$
\begin{aligned}
T\left(y_{0}\right)= & Y_{v}\left(y_{0}\right) Q\left(y_{0}\right) \\
= & Y_{v}\left(y_{0}\right)(\sqrt{2 e}) V_{0} \iint_{\Omega} \frac{x}{L_{0}} e^{-\left(x / L_{0}\right)^{2}} \\
& \times\left[1-\operatorname{erf}\left(-\frac{z}{L^{z}}\right)\right] d x d z,
\end{aligned}
$$

where $Q$ is the volume flux within $\Omega$, the blue region in Fig. 4, at the latitude (cross-isobath location) of the eddy's center; $Q$ must be scaled down by $Y_{v}$ to obtain the actual transport $T$ at the desired latitude.

The term $Y_{v}\left(y_{0}\right)$ is determined empirically using 30 simulations with $0.1 \lesssim H_{\mathrm{sb}} / L^{z} \lesssim 0.4$ (Table 1). To do so, we regress the diagnosed transport, the true value of $T\left(y_{0}\right)$, against the overestimate $Q\left(y_{0}\right)$ at different nondimensional isobaths $y / R$. A weighted least squares regression determines the best fit and its $95 \%$ confidence bounds:

$$
\text { diagnosed flux, } T=m Q+c \text {. }
$$

The weights used are the standard error of each average estimate. At all isobaths, the $y$ intercept of the regression line $c$ includes 0 within its error bounds; $Y_{v}\left(y_{0}\right)=m(y / R)$ by comparing (11) and (12). However, $Y_{v}$ also includes errors associated with the choice of bounding contour for the eddy core, errors in the estimate of eddy scales, and those associated with ignoring the apparent intrusion into the eddy. Thus, $Y_{v}$ is not 1 at the latitude of the eddy's center. In Figs. 13a and 13b, the predicted overestimate $Q$ is compared against the diagnosed average transport at two nondimensional isobaths: at the shelf break, $y / R=0$, and offshore of it, $y / R=0.67$. The latter is typical of all isobaths offshore of the shelf break.

The variation of the regression slope $m\left(\equiv Y_{v}\right)$ with isobath $y / R$ reflects the shape of the eddy in the cross-isobath direction, decaying with distance away from the eddy's center (Fig. 13c). The red dashed line in Fig. 13c is a perfect Gaussian curve centered at $y / R=1$, the eddy center, and amplitude equal to the maximum value of $m$. The Gaussian decay captures much of the variation in $m$; the eddy is very nearly Gaussian in the cross-isobath direction. However, the monotonic decrease of $m$ away from the eddy's center is interrupted at the shelf break. We have assumed that the eddy's center is one radius away from the shelf break (assumption iv). This assumption is violated by the eddy spilling onto the shelf; $m(y / R)$ changes by less than $10 \%$ when changing the integration depth $D$.

For larger values of flux, the points are more uncertain and farther away from the line. These simulations have deeper shelves $(\lambda \sim 0.3)$ and/or stronger eddies (Ro $\sim 0.25)$ that spin up stronger cyclones. These cyclones advect the eddy away and toward the shelf break, making the flux time 

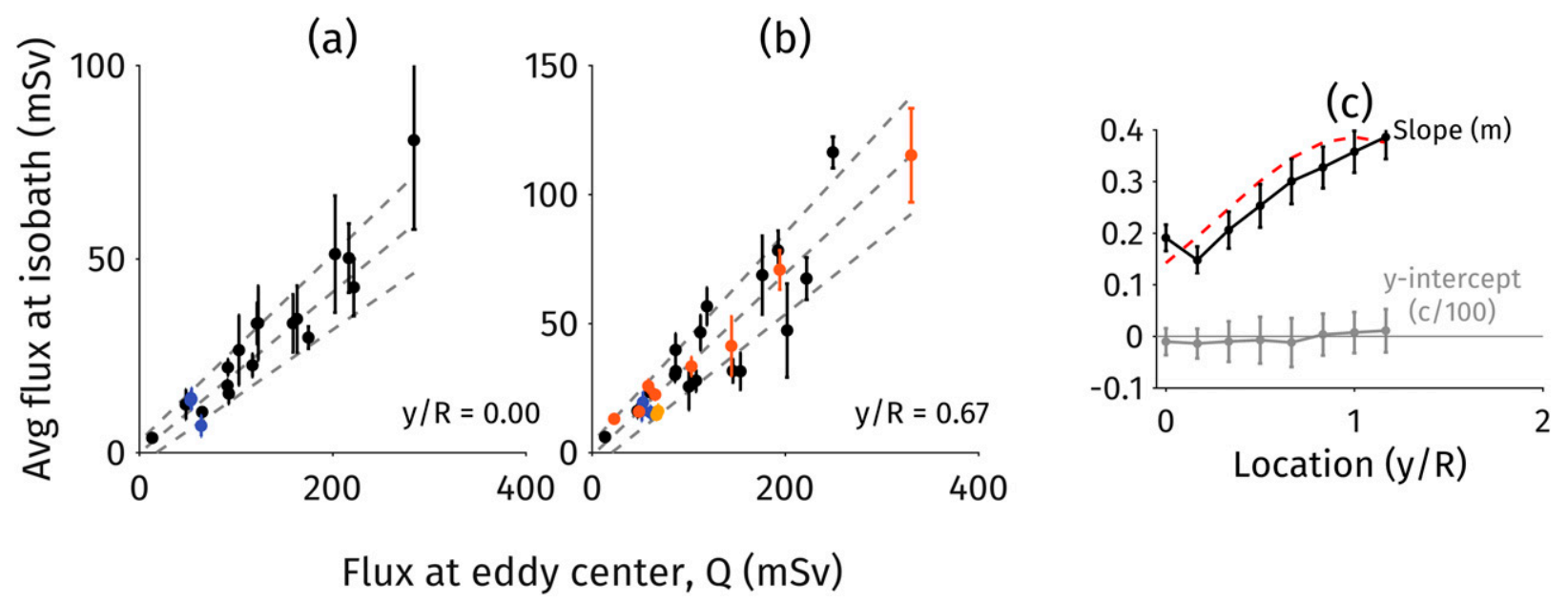

FIG. 13. Parameterization for average flux at an isobath. The first two panels are for particular isobaths: $y / R=(\mathrm{a}) 0$ and (b) 0.67 . Regression lines, diagnosed flux $=m Q+c$, are obtained using weighted least squares with weights being the inverse of the standard error. The dark gray points are inviscid runs, blue points are viscid, and orange points are runs with a sloping shelf. (c) The isobath dependence of the regression slope $m$ and $y$ intercept $c$ (also in Table 3). At all isobaths, the regression coefficient $C_{r}$ is $0.9-0.94$.

series noisier. For warm-core rings, $\lambda \sim 0.1$ and Ro $\sim 0.15$, which places them near the center of each panel. Offshore of the shelf break, the presence of a shelf slope makes no difference, so those simulations are included in the appropriate panels (orange points). At all isobaths (not shown here), correlation coefficient $C_{r}$ between the diagnosed average flux and $Q$ is in the range 0.9-0.94, significantly different from 0 at $99 \%$ confidence, and percentage errors are typically $10 \%-25 \%$.

\section{Discussion}

\section{a. Variations}

The evolution of the eddies remains qualitatively similar for different parameter values, as indicated by the eddy center tracks in Fig. 14.

Bottom friction $\left(r_{f} \neq 0\right)$ generates vorticity at the slope, creating stronger secondary cyclones when compared to inviscid runs, making the eddy's track loopier. For larger values of bottom friction, the stronger cyclone advects the eddy more westward as it traverses around the eddy. Both friction and hydraulic arrest contribute to the generation of cyclonic vorticity at the slope.

The most influential parameter is $\lambda=H_{\mathrm{sb}} / L^{z}$, the ratio of shelfbreak depth to the eddy's vertical scale (Fig. 15). So far, we have focused on the range $0.1 \lesssim \lambda \lesssim 0.4$ (Figs. 15b,e), where the cross-shelfbreak flow has the filament/vortex character observed in some satellite images. Stronger shelf-slope water vortices are created by deeper shelves and stronger eddies. Away from the eddy, there is some transport associated with the eddying leakage. For $\lambda \lesssim 0.1$, the export of shelf water across the shelf break is dominated by an apparent instability at the ring's edge. The instability makes the vertically integrated instantaneous cross-shelfbreak velocity change sign frequently around the eddy's center (Fig. 15d). The along-isobath sign reversal of the cross-shelf break is also present in the time-averaged offshore flow (not shown). One plausible explanation is that reducing the water depth changes the mean PV gradient by increasing the topographic PV gradient: $f_{0} / H_{\mathrm{sb}} \nabla H$. This could reduce the wavelength of the most unstable mode. Ramp et al. (1983) studied what appear to be similar instability waves in SST images and attributed them to the barotropic instability resulting from the enhanced shear between the ring flow and the shelfbreak front jet. Further work is required to clarify the nature of the instability and parameterize the cross-shelfbreak transport in this case. Depending on choices, $H_{\mathrm{sb}} / L^{z}$ for warm-core rings at the Mid-Atlantic Bight seems to be between 0.1 and 0.2, near the transition in behavior. For $0.4 \lesssim \lambda \lesssim 1$, the interaction resembles that of an eddy with a ridge, and the eddy splits across the shelf break (Cherian 2016; Kamenkovich et al. 1996). The sharp dip in the $H_{\mathrm{sb}}=300-\mathrm{m}$ track in Fig. 14 is when that eddy starts to split across the shelf break (see Fig. 15c). When $\lambda \sim 1$, the eddy continues across the shelf break on to the shelf almost unimpeded (Cherian 2016).

All experiments described so far have a southern coast. With a western coast, the slope blocks both the radiated Rossby waves and the wake cyclone of the eddy (Figs. 16a-c). The waves spin up a cyclonic flow field over the slope that transports slope water across isobaths (Fig. 16c). Further, the anticyclonic eddy translates 


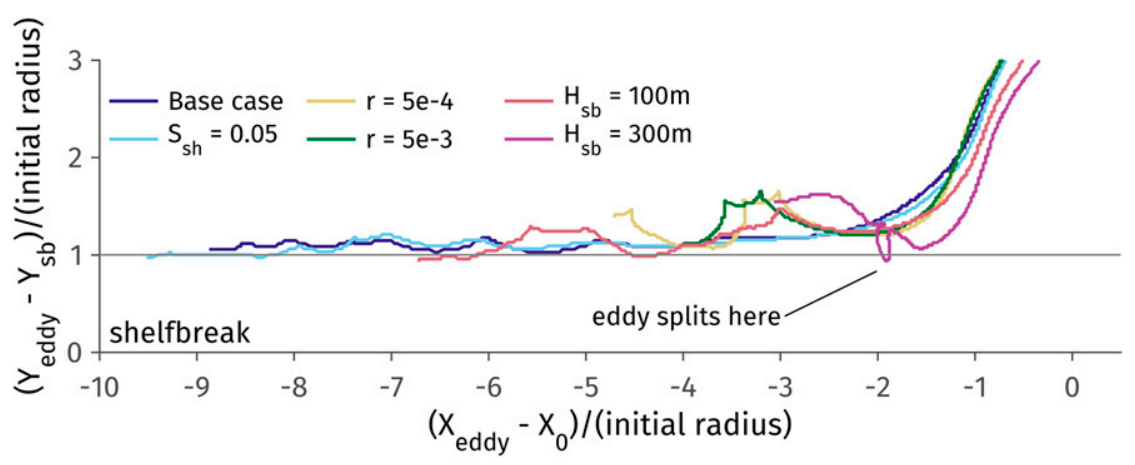

FIG. 14. Tracks of the eddy center (SSH maxima). All simulations have an eddy of $25-\mathrm{km}$ radius, $400-\mathrm{m}$ vertical scale, and Ro $\sim 0.1$. The $x$ and $y$ axes show the location of the eddy center relative to the shelf break in $y$ and the eddy's initial location in $x$. Both axes are normalized by the initial radius of the eddy. All but one track (dark red, $H_{\mathrm{sb}}=300 \mathrm{~m}$ ) asymptote to $y=1$, indicating that the eddy's southern edge is at the shelf break and cannot cross onto the shelf. The base case has no bottom friction $\left(r_{f}=0\right)$ and a flat shelf $\left(S_{\mathrm{sh}}=0\right)$ with a shelfbreak depth of $50 \mathrm{~m}$. Addition of bottom friction results in generation of stronger cyclonic vorticity at the slope and greater meridional motion of the eddy (section 5b). Similar behavior occurs when increasing shelfbreak depth, resulting in greater stretching of shelf water and stronger cyclonic vortices. As the shelf gets deeper $(300 \mathrm{~m})$, the track gets complicated with the eddy splitting across the shelf break (dip in dark blue track). A sloping shelf does not change the trajectory at all.

northward toward these flow features due to the image effect (Nof 1999). So unlike with a southern coast, the eddy is not interacting with undisturbed slope fluid (contrast the dyed slope fluid in Figs. 2 and 16). However, the evolution remains similar. The mechanism of section $5 b$ still results in shelf water intruding into the eddy, creating a subsurface maximum in offshore transport. The exported shelf water originates from south of the eddy, that is, downstream in the coastal-trapped wave sense, just as for a southern coast. There is also an along-shelf jet

\section{Along-shelf profile of cross-isobath transport at shelfbreak}
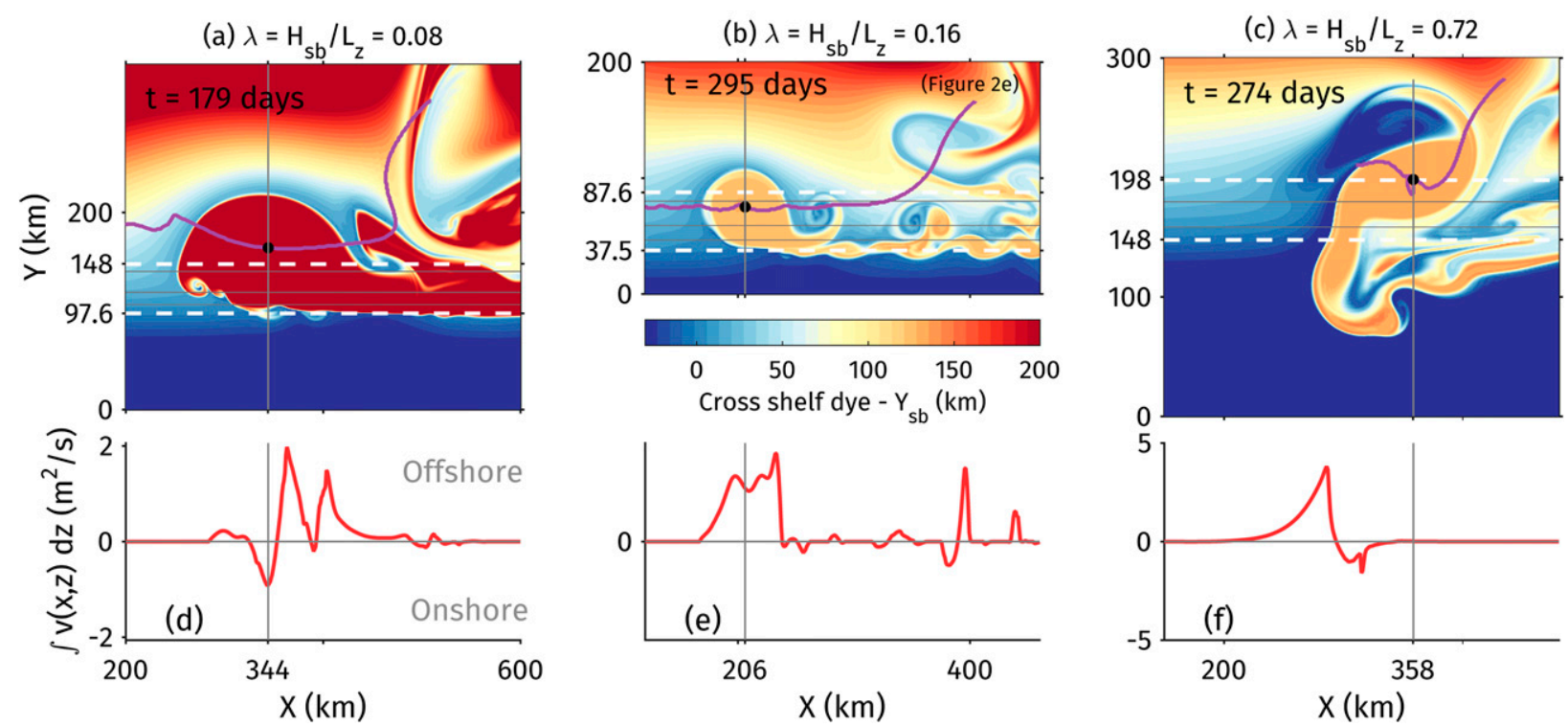

FIG. 15. Surface dye fields and instantaneous vertically integrated transport of shelf water across the shelf break, illustrating regime change for increasing $\lambda=H_{\mathrm{sb}} / L^{z}$ (simulations ew-4341, ew-34, and ew-2341). (a) For $\lambda \lesssim 0.1$, the flux occurs due to the apparent baroclinic instability of the front between eddy and shelf waters. The offshore flow has multiple zero crossings around the eddy's center. (b) For deeper $H_{\mathrm{sb}}$, the profile has the filamentary shape of a contour advected by an eddylike flow field. There is some transport driven by the leakage at the shelf break. (c) The eddy splits across the shelf break and advects eddy water on to the shelf. The negative spike showing onshore transport of shelf water due to a thin filament moving back on to the shelf. 

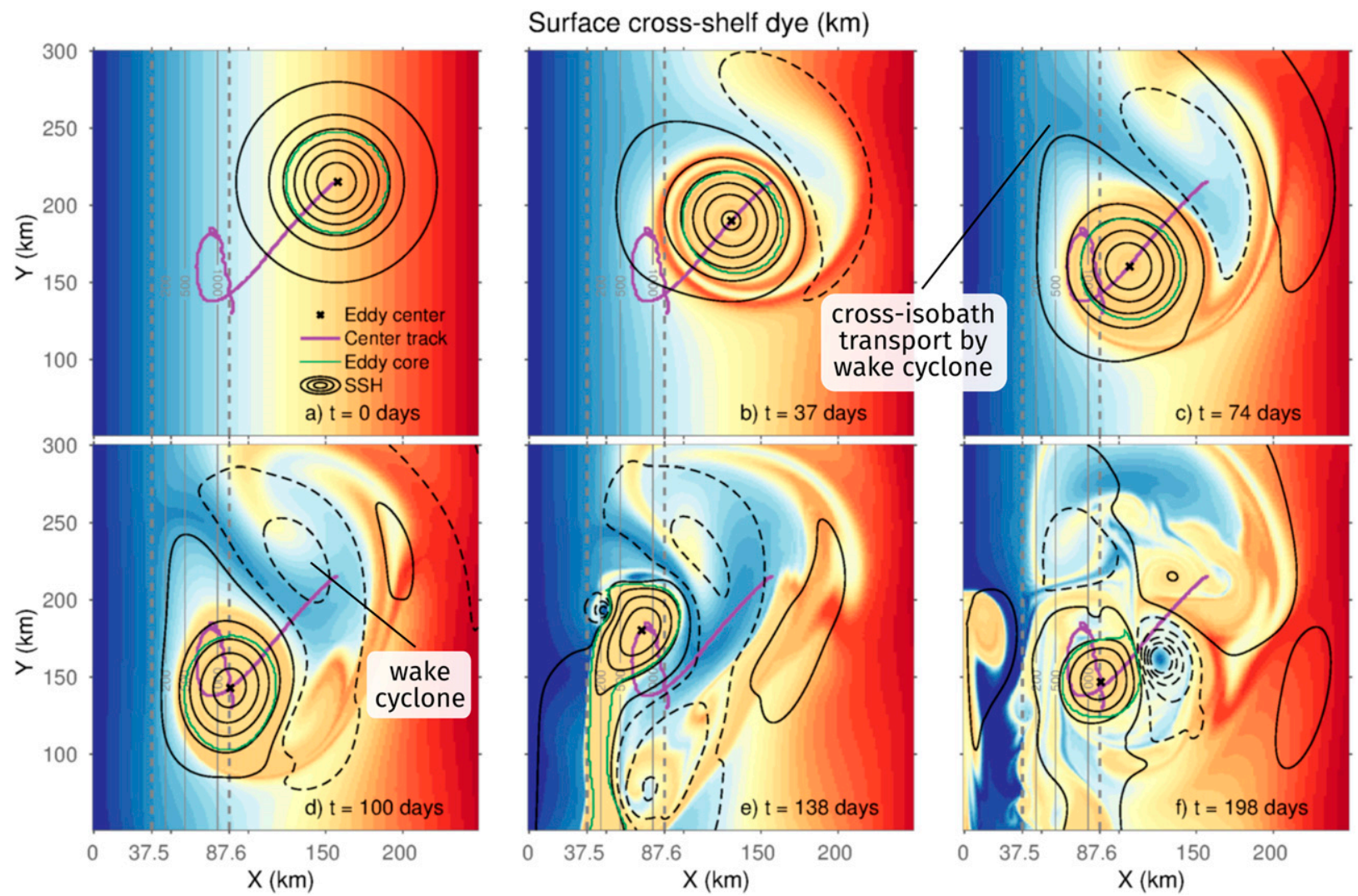

FIG. 16. Surface contours for a simulation with a western coast (ns-35, analogous to Fig. 2). The cross-shelf dye field is in color and SSH is contoured in black (dashed contours indicate negative values). Westward radiation of Rossby waves spins up motions over the continental slope. In contrast, the slope fluid is undisturbed in simulations with a southern coast.

containing eddy water that moves downstream in the coastal-trapped wave sense. Thus, qualitatively, the results described earlier still hold.

When a cyclone interacts with shelf-slope topography to the north, the cross-isobath transport is surface intensified. The difference is that the cyclone is a dense water anomaly that raises isopycnals near itself. Anticyclones make a shelf-slope water parcel sink along depressed isopycnals as it moves offshore over the unstable cyclonic anomaly. This creates an apparent intrusion at depth (Fig. 6). On the other hand, when cyclones advect a shelf-slope water parcel offshore, it rises along uplifted isopycnals over the near-surface eddy water. The shelfslope water intrusion now is at the surface, resulting in a surface-intensified transport profile (Cherian 2016).

\section{b. Observational evidence}

Regardless of coastal orientation, there are three features that characterize the interaction of anticyclones with shelf-slope topography: 1) a subsurface peak in offshore transport of shelf-slope water at every isobath offshore of the shelf break, 2) the leakage of eddy water as an along-shelf jet, and 3) intrusions of shelf-slope water into the eddy that eventually form stacked cyclones and dipoles. Are there observations of such behavior?

Only two observational papers utilize velocity cross sections from ADCPs to estimate the offshore transport directly: Joyce et al. (1992) and Lee and Brink (2010). In the former, it is unclear whether integrating the velocity field over shelf-slope water would result in a subsurface peak. The ADCP data of Lee and Brink (2010) show a surface-intensified velocity field with a slight subsurface maximum. Both observations suffer from being single snapshots of an unsteady flow field. Lee and Brink (2010), in particular, measured velocities right as the ring separated from the Gulf Stream. At the time of observation, it is likely that offshore transport was still filamentary as in the initial panels of Fig. 2.

The along-shelf leakage has received the least attention of the three. Oey and Zhang (2004) discussed observations of a bottom-intensified, along-slope jet near a Loop Current ring at an oil industry site in the Gulf of Mexico. Lee and Brink (2010) observed a growing warm saline intrusion that appears to break off into a small 
warm eddy at the 100-m isobath on George's Bank (Fig. 1). Such evolution appears to be similar to that which forms the warm eddies propagating along the shelf break in Figs. 2e and 2f. High-salinity intrusions on George's Bank are commonly, but not always, associated with Gulf Stream warm-core rings near the shelf break (Mountain et al. 1989; Churchill et al. 2003). Ullman et al. (2014) observed an anomalous, near-bottom, warm saline water mass at the 30- and 50-m isobaths in Rhode Island Sound, roughly $100 \mathrm{~km}$ from the shelf break. Its water properties were similar to a water mass observed a month earlier on the continental slope after a Gulf Stream warm-core ring had hit the shelf break. Presumably, the leakage rolled up into an eddy, as in Lee and Brink (2010), that then penetrated far on to the shelf for reasons unconnected with the ring. Zhang and Gawarkiewicz (2015) recently reported glider observations and SST images of the leakage at the Mid-Atlantic Bight shelf break. Their adjoint model analysis showed that water in the leakage originated in the edge of the eddy, that is, the annulus, as in Shi and Nof (1993), which agrees with what we see.

There are two discrepancies between our results and typical SST images of the northwest Atlantic (e.g., Fig. 1). In our simulations, all eddies eventually start creating shelf-water cyclones. Simultaneously, in the model, there is always leakage of eddy water along the shelf break. Both features are not always observed in SST data. They require that the sloping bottom impose a lateral boundary condition that diverts the eddy's flow, causing the loss of annulus fluid. In the Mid-Atlantic Bight, there exists shelf water offshore of the shelf break because the shelfbreak front tilts and outcrops offshore of the shelf break. Thus, offshore transport of shelf water does not require that the eddy be at the shelf break.

If the eddy is not close enough to the slope, then it will not shed much fluid. Instead, it will wrap the shelf water around itself as a filament, like the ambient water swirled around in the first three panels of Fig. 2. Since the shelf water is generally denser than ambient slope water, the densest shelf water in the filament will appear as a subsurface core in observational cross sections. Observations of subsurface cores of $32 \mathrm{psu}, 10^{\circ} \mathrm{C}$ water, typical of near-bottom cold pool shelf water (Houghton et al. 1982), are common (e.g., Nelson et al. 1985; Tang et al. 1985; Ramp et al. 1983; Garfield and Evans 1987). These cores are outside the eddy. If the subsurface core is embedded in the eddy as in Churchill et al. (1986, their Fig. 8), recreated in Fig. 17a, then the mechanism of section 5 is likely responsible. Figure 17a compares favorably with a $y-z$ section of eddy dye in Fig. 17b. In Fig. 17a, the warm-core ring is in direct contact with the upper slope between the 100- and 150-m isobaths; the interaction is likely similar to the conducted simulations.
The way our experiments are set up, the $\beta$ plane continuously forces the eddy into the topography, the eddy always gets to the shelf break, and the eddy-slope interaction is always severe. In the real ocean, this does not happen. The presence of other rings and a meandering Gulf Stream makes the trajectory of actual warm-core rings far more complicated than that solely determined by $\beta$-plane translation. Thus, we do not expect the mechanism of section 5 to always occur, explaining why the subsidiary cyclones observed by Kennelly et al. (1985) are not stacked. There seem to be no reported observations of stacked cyclones or dipoles between the shelf break and Gulf Stream.

\section{c. The shelfbreak front}

An important factor ignored herein is the presence of a shelfbreak front. Given the much larger velocity and vorticity signatures of the eddy, it is likely that the front is not a substantial barrier to the offshore flow imposed by the eddy. Indeed, Cenedese et al. (2013) observed that the jet associated with the shelfbreak front had both reversed direction and increased transport magnitude from 0.29 to $0.39 \mathrm{~Sv}$ during a period of ring interaction. Whether the onshore transport of eddy water matters to shelf-water budgets, defined using density class, depends on whether the leaked eddy water can break through the front. Thus, we conjecture that the front is a more effective barrier where the eddy leaks on to the shelf. This hypothesis will need to be checked with higherresolution (200-500 m) model runs that are capable of resolving the baroclinic instability of the front.

\section{d. An offshore flux estimate for the Mid-Atlantic Bight}

Using the methodology of section 8 for simulations with sloping shelves yields a regression slope at shelf break $m(y / R=0)$ of 0.09 , smaller than that obtained for a flat shelf of 0.19 (Cherian 2016, and Table 3, respectively). More in-depth discussion of simulations with a sloping shelf is postponed to a future paper [also discussed in Cherian (2016)]. For now, we will use the more appropriate regression slope to estimate the magnitude of eddy-driven, offshore, shelf-water transport for the Mid-Atlantic Bight.

Using ADCP observations of warm-core ring 99C, Wei et al. (2008) obtain $V_{0}=1.2 \mathrm{~m} \mathrm{~s}^{-1}$ and a radius to maximum velocity of $45 \mathrm{~km}$. For a Gaussian density anomaly, the radius to maximum velocity is $L_{0} / \sqrt{2}$, so we use $L_{0}=45 \sqrt{2} \mathrm{~km} \approx 65 \mathrm{~km}$. We assume $L^{z}$ to be $1000 \mathrm{~m}$ based on observations in Joyce (1984, his Fig. 10). With these choices, the parameterization in (11) predicts an average offshore transport of $0.3 \mathrm{~Sv}$ across the shelf break if the ring is at the shelf break (section 8). For a different eddy, Joyce and Kennelly (1985) report $V_{0}=1.8 \mathrm{~m} \mathrm{~s}^{-1}$ and 
(a) Oleander XBT Temperature (C)
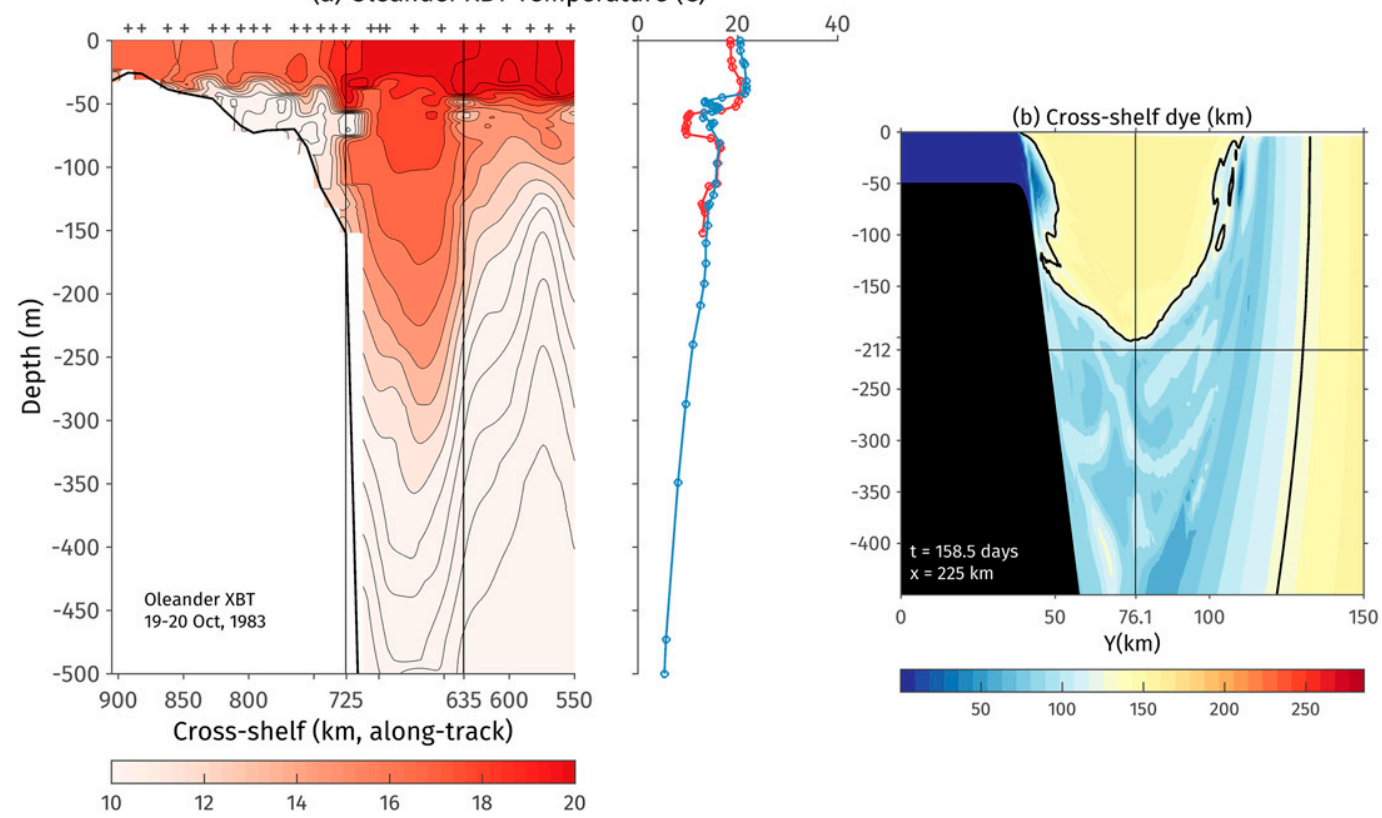

FIG. 17. (a) Temperature section from CMV Oleander XBT data (Flagg et al. 1998) showing shelf-water intrusions in a warm-core ring (after Churchill et al. 1986). The $10^{\circ} \mathrm{C}$ water is indicative of cold pool water on the MidAtlantic Bight shelf. A similar intrusive feature appears on the other side of the ring, but with higher temperature. The two lines are vertical profiles of through temperature the two intrusions. (b) Model $y-z$ section of cross-self dye through the eddy center showing shelf-slope water intrusions into the eddy (ew-36).

$L_{0}=100 \mathrm{~km}$. Equation (11) then predicts an offshore flux of $0.7 \mathrm{~Sv}$. Both values are approximately the same magnitude or much larger than the mean along-isobath flow on the shelf (less than $0.5 \mathrm{~Sv}$ onshore of the shelf break; Lentz 2008) and the mean transport in the shelfbreak front (0.24 $0.45 \mathrm{~Sv}$; Linder and Gawarkiewicz 1998). So, if a ring is at the shelf break, there should be a large perturbation to the shelf flow near the shelf break. This prediction agrees with Cenedese et al. (2013) who observed reversal of the shelfbreak jet near the ring during a period of ring interaction.

Prior observational estimates of shelf-water transport span a large range of values. In particular, the estimates depend strongly on the choice of a maximum-salinity threshold value used to identify shelf water (Cherian 2016). For example, Joyce et al. (1992) report values of $0.02,0.4$, and $0.9 \mathrm{~Sv}$ for salinity thresholds 33,34 , and 35 . Lee and Brink (2010) report a value of $0.07 \mathrm{~Sv}$ for a salinity threshold of 33 and Cenedese et al. (2013) estimated an offshore transport of $1 \mathrm{~Sv}$ for a salinity threshold of 34.9. Our estimate is thus extremely large for a threshold of 33 but consistent with prior estimates if the chosen salinity threshold is around 35.

Another way to evaluate the prediction is to use existing volume budgets for the shelf. The Mid-Atlantic Bight volume budget of Brink (1998) requires a total offshore flux of shelf water in the range of $0.04-0.11 \mathrm{~Sv}$. Over a year, this flux exports $1.3 \times 10^{12}-3.5 \times 10^{12} \mathrm{~m}^{3}$ of shelf water. If all of this volume were exported by warmcore rings, it would correspond to 50 to 130 days of ring interaction with the shelf, again assuming that the eddy is right at the shelf break and transports $0.3 \mathrm{~Sv}$ of water on average throughout the interaction. In comparison, Halliwell and Mooers (1979) estimated that an average of 3-5 eddies affected the shelfbreak front every year with a residence time of 2-3 weeks, approximately 40 to 105 days of eddy-front interaction. If the above assumptions hold, warm-core rings could accomplish all the required shelf-water export, an unlikely result given the

TABLE 3. Regression slopes at all isobaths for the average flux parameterization.

\begin{tabular}{llllll}
\hline \hline$y / R$ & 0 (sloping shelf) & 0 (flat shelf) & 0.16 & 0.33 & 0.5 \\
\hline$m$ & $0.09 \pm 0.03$ & $0.19 \pm 0.03$ & $0.15 \pm 0.03$ & $0.21 \pm 0.04$ & $0.25 \pm 0.04$ \\
$y / R$ & & 0.67 & 0.83 & 1 & 1.17 \\
$m$ & & $0.30 \pm 0.04$ & $0.33 \pm 0.04$ & $0.36 \pm 0.04$ & $0.39 \pm 0.04$ \\
\hline
\end{tabular}


number of possible cross-shelfbreak exchange mechanisms (Brink 2016). On the other hand, using $7 \mathrm{yr}$ of SST imagery, Garfield and Evans (1987) estimate that streamers are observed $70 \%$ of the time, roughly 250 days a year. All this reinforces two points: 1) Our $0.3-\mathrm{Sv}$ prediction is likely an overestimate because the simulations always result in severe eddy-shelf interaction. 2) The presence of shelf water offshore of the shelf break means that a ring need not significantly interact with the shelf for a shelf-water streamer to be present in satellite imagery (Fig. 1; Beardsley et al. 1985).

The episodic, unpredictable nature of ring-slope interaction makes a thorough observational test of the parameterization in (11) difficult. The integral time scale for the flux time series in Fig. 3 is roughly 1.3-1.4 times the eddy turnover time scale (the ratio of length scale to velocity scale), and the turnover time scale for warm-core rings is approximately $2-2.5$ days. Thus, to obtain statistically independent snapshots of the flow field for averaging, an along-isobath transect would need to be repeated many times with approximately 4-day separation.

\section{Conclusions}

Using idealized numerical simulations, we have shown that for $0.1 \lesssim H_{\mathrm{sb}} / L_{z} \lesssim 0.4$, the interaction of an eddy with shelf-slope topography is very similar to its interaction with a vertical wall described in Shi and Nof (1993). In doing so, the eddy moves along shelf in the image-effect direction and develops apparent intrusions of shelf-slope water (Fig. 8). The intrusions are quite similar to Container Motor Vessel (CMV) Oleander XBT observations that show a shelf-water parcel embedded in a Gulf Stream warm-core ring (Churchill et al. 1986). They result from shelf-slope water being advected over an unstable cyclonic anomaly propagating on the eddy at depth. The intrusions have two consequences: 1) the vertical profile of offshore transport has a subsurface maximum (Fig. 5), and 2) shelf-slope water is trapped in stacked cyclones that contain shelfslope water down to shelfbreak depth (roughly) and eddy water below (Fig. 9). These cyclones combine with water extracted from the eddy's core to form dipoles that then move away from the shelf break (Fig. 2). The shelf water is thus permanently exported. Over the shelf, an along-shelf flow supplies shelf water to the outflow (Fig. 12). We have also laid out a simple parameterization for the average offshore transport magnitude that could be used with satellite observations. These results need to be verified with observations.

Acknowledgments. This paper constitutes part of DAC's Ph.D. thesis. Steve Lentz's detailed reading, suggestions, and questions vastly improved the quality of this manuscript. Stimulating discussions with Glenn Flierl and Amala Mahadevan are also gratefully acknowledged, as are many conversations with Isabela LeBras and Rebecca H. Jackson. Jacob Forsyth graciously shared his quality controlled compilation of the CMV Oleander XBT data. Comments by two anonymous reviews helped improve the clarity of the manuscript. We acknowledge high-performance computing support from Yellowstone (ark:/85065/d7wd3xhc) provided by NCAR's Computational and Information Systems Laboratory, sponsored by the National Science Foundation. The research presented here was funded by NSF Grants OCE-1059632 and OCE-1433953. Funding support from the Academic Programs Office, and WHOI is also gratefully acknowledged.

\section{REFERENCES}

Beardsley, R. C., D. C. Chapman, K. H. Brink, S. R. Ramp, and R. J. Schlitz, 1985: The Nantucket Shoals Flux Experiment (NSFE79). Part I: A basic description of the current and temperature variability. J. Phys. Oceanogr., 15, 713-748, doi:10.1175/1520-0485(1985)015<0713:TNSFEP > 2.0.CO;2.

Brink, K. H., 1998: Deep sea forcing and exchange processes. The Global Coastal Ocean: Processes and Methods, K. H. Brink, and A. R. Robinson, Eds., The Sea-Ideas and Observations on Progress in the Study of the Seas, Vol. 10, John Wiley and Sons, 151-167.

, 2016: Cross-shelf exchange. Annu. Rev. Mar. Sci., 8, 59-78, doi:10.1146/annurev-marine-010814-015717.

Cenedese, C., R. E. Todd, G. G. Gawarkiewicz, W. B. Owens, and A. Y. Shcherbina, 2013: Offshore transport of shelf waters through interaction of vortices with a shelfbreak current. J. Phys. Oceanogr., 43, 905-919, doi:10.1175/ JPO-D-12-0150.1.

Chapman, D. C., and K. H. Brink, 1987: Shelf and slope circulation induced by fluctuating offshore forcing. J. Geophys. Res., 92, 11 741-11 759, doi:10.1029/JC092iC11p11741.

Chelton, D. B., M. G. Schlax, and R. M. Samelson, 2011: Global observations of nonlinear mesoscale eddies. Prog. Oceanogr., 91, 167-216, doi:10.1016/j.pocean.2011.01.002.

Chen, K., R. He, B. S. Powell, G. G. Gawarkiewicz, A. M. Moore, and H. G. Arango, 2014: Data assimilative modeling investigation of Gulf Stream warm core ring interaction with continental shelf and slope circulation. J. Geophys. Res. Oceans, 119, 5968-5991, doi:10.1002/2014JC009898.

Cherian, D. A., 2016: When an eddy encounters shelf-slope topography. Ph.D. thesis, Masschusetts Institute of Technology and Woods Hole Oceanographic Institution, 135 pp.

Churchill, J. H., P. C. Cornillon, and G. W. Milkowski, 1986: A cyclonic eddy and shelf-slope water exchange associated with a Gulf Stream warm-core ring. J. Geophys. Res., 91, 96159623, doi:10.1029/JC091iC08p09615.

_ J. P. Manning, and R. C. Beardsley, 2003: Slope water intrusions onto Georges Bank. J. Geophys. Res., 108, 8012, doi:10.1029/2002JC001400.

Dewar, W. K., P. Berloff, and A. M. Hogg, 2011: Submesoscale generation by boundaries. J. Mar. Res., 69, 501-522, doi:10.1357/ 002224011799849345 . 
Early, J. J., R. M. Samelson, and D. B. Chelton, 2011: The evolution and propagation of quasi-geostrophic ocean eddies. J. Phys. Oceanogr., 41, 1535-1555, doi:10.1175/2011JPO4601.1.

Evans, R. H., K. S. Baker, O. B. Brown, and R. C. Smith, 1985: Chronology of warm-core ring 82B. J. Geophys. Res., 90, 88038811, doi:10.1029/JC090iC05p08803.

Flagg, C. N., G. Schwartze, E. Gottlieb, and T. Rossby, 1998: Operating an acoustic Doppler current profiler aboard a container vessel. J. Atmos. Oceanic Technol., 15, 257-271, doi:10.1175/1520-0426(1998)015<0257:OAADCP>2.0.CO;2.

Flierl, G. R., M. E. Stern, and J. A. Whitehead, 1983: The physical significance of modons: Laboratory experiments and general integral constraints. Dyn. Atmos. Oceans, 7, 233-263, doi:10.1016/ 0377-0265(83)90007-6.

Frolov, S. A., G. G. Sutyrin, G. D. Rowe, and L. M. Rothstein, 2004: Loop Current eddy interaction with the western boundary in the Gulf of Mexico. J. Phys. Oceanogr., 34, 2223-2237, doi:10.1175/1520-0485(2004)034<2223:LCEIWT>2.0.CO;2.

Garfield, N., and D. L. Evans, 1987: Shelf water entrainment by Gulf Stream warm-core rings. J. Geophys. Res., 92, $13003-$ 13 012, doi:10.1029/JC092iC12p13003.

Halliwell, G. R., and C. N. K. Mooers, 1979: The space-time structure and variability of the shelf water-slope water and Gulf Stream surface temperature fronts and associated warm-core eddies. J. Geophys. Res., 84, 7707-7725, doi:10.1029/JC084iC12p07707.

Houghton, R. W., R. Schlitz, R. C. Beardsley, B. Butman, and J. L. Chamberlin, 1982: The Middle Atlantic Bight cold pool: Evolution of the temperature structure during summer 1979. J. Phys. Oceanogr., 12, 1019-1029, doi:10.1175/ 1520-0485(1982)012<1019:TMABCP >2.0.CO;2.

Joyce, T. M., 1984: Velocity and hydrographic structure of a Gulf Stream warm-core ring. J. Phys. Oceanogr., 14, 936-947, doi:10.1175/1520-0485(1984)014<0936:VAHSOA > 2.0.CO;2.

— , and M. A. Kennelly, 1985: Upper-ocean velocity structure of Gulf Stream warm-core ring 82B. J. Geophys. Res., 90, 88398844, doi:10.1029/JC090iC05p08839.

— J. K. Bishop, and O. B. Brown, 1992: Observations of offshore shelf-water transport induced by a warm-core ring. Deep-Sea Res., 39A, S97-S113, doi:10.1016/S0198-0149(11)80007-5.

Kamenkovich, V. M., Y. P. Leonov, D. A. Nechaev, D. A. Byrne, and A. L. Gordon, 1996: On the influence of bottom topography on the Agulhas eddy. J. Phys. Oceanogr., 26, 892-912, doi:10.1175/1520-0485(1996)026<0892:OTIOBT >2.0.CO;2.

Kennelly, M. A., R. H. Evans, and T. M. Joyce, 1985: Small-scale cyclones on the periphery of a Gulf Stream warm-core ring. J. Geophys. Res., 90, 8845-8857, doi:10.1029/JC090iC05p08845.

Lee, C. M., and K. H. Brink, 2010: Observations of storm-induced mixing and Gulf Stream Ring incursion over the southern flank of Georges Bank: Winter and summer 1997. J. Geophys. Res., 115, C08008, doi:10.1029/2009JC005706.

Lentz, S. J., 2008: Observations and a model of the mean circulation over the Middle Atlantic Bight continental shelf. J. Phys. Oceanogr., 38, 1203-1221, doi:10.1175/2007JPO3768.1.

_ 2010: The mean along-isobath heat and salt balances over the Middle Atlantic Bight continental shelf. J. Phys. Oceanogr., 40, 934-948, doi:10.1175/2009JPO4214.1.

Linder, C. A., and G. G. Gawarkiewicz, 1998: A climatology of the shelfbreak front in the Middle Atlantic Bight. J. Geophys. Res., 103, 18 405-18 423, doi:10.1029/98JC01438.

Marchesiello, P., J. C. McWilliams, and A. F. Shchepetkin, 2001: Open boundary conditions for long-term integration of regional oceanic models. Ocean Modell., 3, 1-20, doi:10.1016/ S1463-5003(00)00013-5.
Mason, E., M. J. Molemaker, A. F. Shchepetkin, F. Colas, J. C. McWilliams, and P. Sangrà, 2010: Procedures for offline grid nesting in regional ocean models. Ocean Modell., 35, 1-15, doi:10.1016/j.ocemod.2010.05.007.

McWilliams, J. C., and G. R. Flierl, 1979: On the evolution of isolated, nonlinear vortices. J. Phys. Oceanogr., 9, 1155-1182, doi:10.1175/1520-0485(1979)009<1155:OTEOIN > 2.0.CO;2.

Mountain, D. G., M. Pastuszak, and D. A. Busch, 1989: Slope water intrusion to the Great South Channel during autumn, 1977-85. J. Northwest Atl. Fish. Sci., 9, 97-102. [Available online at http:// journal.nafo.int/dnn/Volumes/Articles/ID/117/Slope-WaterIntrusion-to-the-Great-South-Channel-During-Autumn-1977-85.]

Nelson, D. M., and Coauthors, 1985: Distribution and composition of biogenic particulate matter in a Gulf Stream warmcore ring. Deep-Sea Res., 32A, 1347-1369, doi:10.1016/ 0198-0149(85)90052-4.

Nof, D., 1983: On the migration of isolated eddies with application to Gulf Stream rings. J. Mar. Res., 41, 399-425, doi:10.1357/ 002224083788519687.

1988: Eddy-wall interactions. J. Mar. Res., 46, 527-555, doi:10.1357/002224088785113540.

, 1999: Strange encounters of eddies with walls. J. Mar. Res., 57, 739-761, doi:10.1357/002224099321560555.

Oey, L.-Y., and H. Zhang, 2004: The generation of subsurface cyclones and jets through eddy-slope interaction. Cont. Shelf Res., 24, 2109-2131, doi:10.1016/j.csr.2004.07.007.

Okkonen, S. R., T. J. Weingartner, S. Danielson, D. Musgrave, and G. Schmidt, 2003: Satellite and hydrographic observations of eddy-induced shelf-slope exchange in the northwestern Gulf of Alaska. J. Geophys. Res., 108, 3033, doi:10.1029/2002JC001342.

Olson, D. B., 1991: Rings in the ocean. Annu. Rev. Earth Planet Sci., 19, 283-311, doi:10.1146/annurev.ea.19.050191.001435.

— R. W. Schmitt, M. Kennelly, and T. M. Joyce, 1985: A twolayer diagnostic model of the long-term physical evolution of warm-core ring 82B. J. Geophys. Res., 90, 8813-8822, doi:10.1029/ JC090iC05p08813.

Ramp, S. R., R. C. Beardsley, and R. Legeckis, 1983: An observation of frontal wave development on a shelf-slope/warm core ring front near the shelf break south of New England. J. Phys. Oceanogr., 13, 907-912, doi:10.1175/1520-0485(1983)013<0907: AOOFWD $>2.0 . \mathrm{CO} ; 2$.

Shchepetkin, A. F., and J. C. McWilliams, 2003: A method for computing horizontal pressure-gradient force in an oceanic model with a nonaligned vertical coordinate. J. Geophys. Res., 108, 3090, doi:10.1029/2001JC001047.

— and - 2005: The Regional Oceanic Modeling System (ROMS): A split-explicit, free-surface, topography-followingcoordinate oceanic model. Ocean Modell., 9, 347-404, doi:10.1016/j.ocemod.2004.08.002.

Shi, C., and D. Nof, 1993: The splitting of eddies along boundaries. J. Mar. Res., 51, 771-795, doi:10.1357/0022240933223927.

— , and - 1994: The destruction of lenses and generation of wodons. J. Phys. Oceanogr., 24, 1120-1136, doi:10.1175/ 1520-0485(1994)024<1120:TDOLAG >2.0.CO;2.

Stewart, A. L., and A. F. Thompson, 2015: Eddy-mediated transport of warm circumpolar deep water across the Antarctic shelf break. Geophys. Res. Lett., 42, 432-440, doi:10.1002/2014GL062281.

Talley, L. D., G. L. Pickard, W. J. Emery, and J. H. Swift, 2011: Descriptive Physical Oceanography: An Introduction. 6th ed. Academic Press, 560 pp.

Tang, C. L., A. S. Bennett, and D. J. Lawrence, 1985: Thermohaline intrusions in the frontal zones of a warm-core ring 
observed by Batfish. J. Geophys. Res., 90, 8928-8942, doi:10.1029/ JC090iC05p08928.

Ullman, D. S., D. L. Codiga, A. Pfeiffer-Herbert, and C. R. Kincaid, 2014: An anomalous near-bottom cross-shelf intrusion of slope water on the southern New England continental shelf. J. Geophys. Res. Oceans, 119, 1739-1753, doi:10.1002/2013JC009259.

Vukovich, F. M., and E. Waddell, 1991: Interaction of a warm ring with the western slope in the Gulf of Mexico. J. Phys. Oceanogr., 21, 1062-1074, doi:10.1175/1520-0485(1991)021<1062: IOAWRW $>2.0 . \mathrm{CO} ; 2$.

Wang, X., 1992: Interaction of an eddy with a continental slope. Ph.D. thesis, Woods Hole Oceanographic Institute/Massachusetts Institute of Technology Joint Program in Oceanography/Applied Ocean Science and Engineering, 216 pp.

Wei, J., and D.-P. Wang, 2009: A three-dimensional model study of warm core ring interaction with continental shelf and slope. Cont. Shelf Res., 29, 1635-1642, doi:10.1016/ j.csr.2009.05.009.

, — - and C. N. Flagg, 2008: Mapping Gulf Stream warm core rings from shipboard ADCP transects of the Oleander project. J. Geophys. Res., 113, C10021, doi:10.1029/2007JC004694.

Whitehead, J. A., 1985: The deflection of a baroclinic jet by a wall in a rotating fluid. J. Fluid Mech., 157, 79-93, doi:10.1017/ S0022112085002312.

Zhang, W. G., and G. G. Gawarkiewicz, 2015: Dynamics of the direct intrusion of Gulf Stream ring water onto the MidAtlantic Bight shelf. Geophys. Res. Lett., 42, 7687-7695, doi:10.1002/2015GL065530.

Zhang, Y., J. Pedlosky, and G. R. Flierl, 2011: Shelf circulation and cross-shelf transport out of a bay driven by eddies from an open-ocean current. Part I: Interaction between a barotropic vortex and a steplike topography. J. Phys. Oceanogr., 41, 889910, doi:10.1175/2010JPO4496.1. 